Supporting Information for

\title{
Crystallization-Driven Self-Assembly of Block Copolymers having Monodisperse Poly(lactic acid)s with Defined Stereochemical Sequences
}

\author{
Yongbeom Kwon, ${ }^{1}$ and Kyoung Taek Kim ${ }^{1 . *}$
}

\author{
${ }^{1}$ Department of Chemistry, Seoul National University, Seoul 08826, Korea \\ *Correspondence to: ktkim72@,snu.ac.kr
}


General Procedure of Deprotection of the benzyl group by hydrogenation ${ }^{1}$

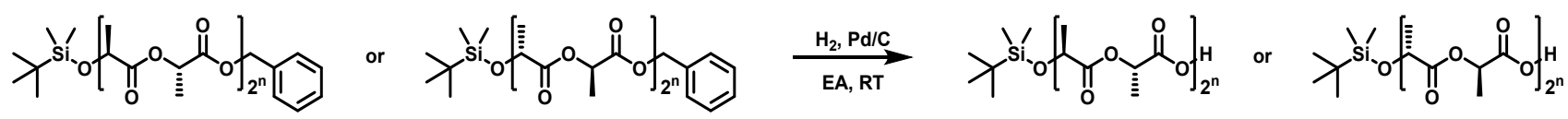

In an oven-dried Schlenk flask, discrete poly(D or L-lactic acid) protected with tert-butyldimethylsilyl (TBDMS) and benzyl groups (1 eq.) was dissolved in ethyl acetate under nitrogen. Palladium on activated charcoal $(10 \% \mathrm{Pd} / \mathrm{C}, 10 \mathrm{wt} \%)$ was added to the solution, and the suspension was purged with nitrogen for $15 \mathrm{~min}$. The nitrogen atmosphere was then changed with hydrogen, and the reaction mixture was stirred for $2 \mathrm{~h}$ at room temperature. The suspension was filtered through a Celite cake to remove $\mathrm{Pd} / \mathrm{C}$. After removal of $\mathrm{Pd} / \mathrm{C}$, the product was obtained by evaporating the solvent under reduced pressure.

\section{General Procedure of Deprotection of the TBDMS group with fluoride ${ }^{1}$}

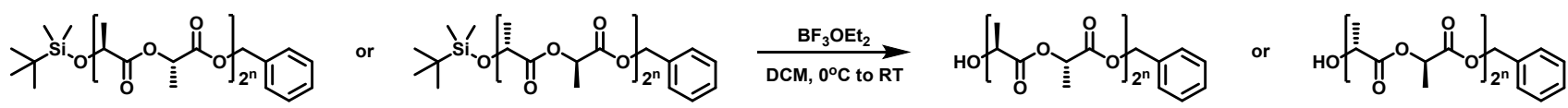

In an oven-dried Schlenk flask, discrete poly(D or L-lactic acid) protected with TBDMS and benzyl groups (1 eq.) was dissolved in dry dichloromethane. Boron trifluoride diethyl etherate (1.5 eq.) was added dropwise to a stirred solution at $0^{\circ} \mathrm{C}$. The reaction mixture was stirred for $4 \mathrm{~h}$ at room temperature. The reaction was quenched with saturated aqueous $\mathrm{NaHCO}_{3}$. The organic layer was washed with $\mathrm{NaHCO}_{3}$, water and brine. The combined organic layer was dried over $\mathrm{MgSO}_{4}$, and the solvent was removed under reduced pressure. The crude product was purified via flash column chromatography using hexane \& ethyl acetate as eluent.

\section{General Procedure of Coupling Reaction: Esterification ${ }^{1}$}

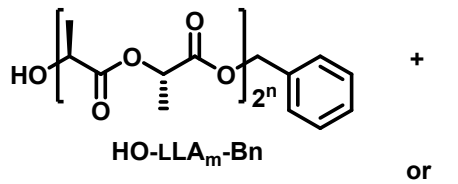

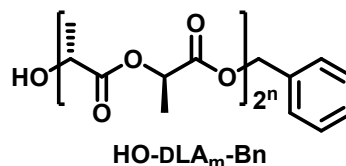<smiles>C=C(OC(=O)C(C)(C)C)C(=O)OC(C)C(=O)OC(C)C(=O)O</smiles>

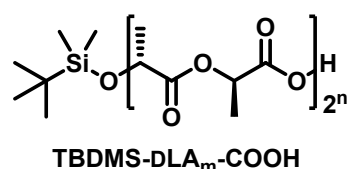

$\underset{\text { EDC } \cdot \mathrm{HCI}, \text { DPTS }}{\longrightarrow}$

DCM
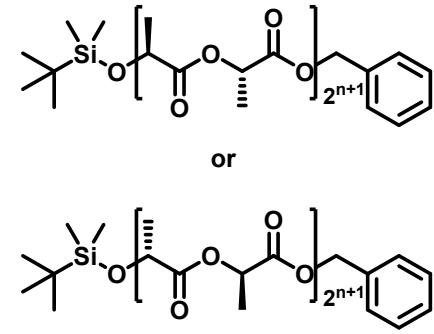

In an oven-dried Schlenk flask, TBDMS-D or LLA $\mathrm{m}^{-C O O H}$ and HO-D or LLA $\mathrm{m}_{\mathrm{m}}-\mathrm{Bn}$ were dissolved in dry dichloromethane. To the solution, $N, N$-dimethylaminopyridinium $p$-toluene sulfonate (DPTS, 0.2 eq.) and 1-(3-dimethylaminopropyl)-3-ethylcarbodiimide hydrochloride (EDC $\cdot \mathrm{HCl}, 2$ eq.) were added. The reaction mixture was stirred overnight at room temperature. The reaction mixture was washed with water and brine. The combined organic layer was dried over $\mathrm{MgSO} 4$, and the solvent was removed under reduced pressure. The crude product was purified via flash column chromatography using hexane \& ethyl acetate as eluent. Products with 32 repeating units or more were purified by preparative-size exclusion chromatography (prep-SEC) with a series of columns using chloroform as 
an eluent.

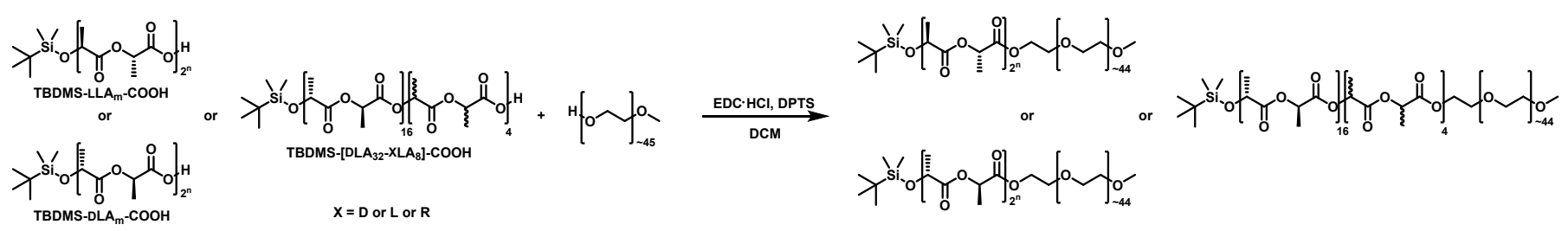

In an oven-dried Schlenk flask, TBDMS-D or LLA $\mathrm{m}_{\mathrm{m}} \mathrm{COOH}$ or TBDMS-[DLA $\left.\mathrm{D}_{32}-\mathrm{XLA}_{8}\right]-\mathrm{COOH}(\mathrm{X}=$ $\mathrm{D}$ or $\mathrm{L}$ or $\mathrm{D} / \mathrm{L}$ ) and poly(ethylene glycol) methyl ether (PEG, 3 eq.) were dissolved in dry dichloromethane. To the solution, DPTS (0.2 eq.) and $\mathrm{EDC} \cdot \mathrm{HCl},(2$ eq.) were added. The reaction mixture was stirred overnight at room temperature. The reaction mixture was washed with water and brine. The combined organic layer was dried over MgSO4, and the solvent was removed under reduced pressure. Products were purified by preparative-size exclusion chromatography (prep-SEC) with a series of columns using chloroform as an eluent.

\section{Synthesis of TBDMS-L or DLA2-Bn}<smiles>C[C@@H]1O[C@H](C)[C@H](C)OC1=O</smiles><smiles>CC[C@H](C)O</smiles><smiles>CC(O)C(=O)O[C@@H](C)C(=O)O</smiles><smiles>CC(O)C(=O)O[C@@H](C)C(=O)OCc1ccccc1</smiles>

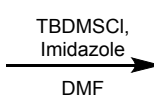<smiles>CC(OC(=O)C(C)OS(C)(C)C(C)(C)C)C(=O)OCc1ccccc1</smiles><smiles>C=C1OC(C)C(=O)OC1C</smiles><smiles>CC(=O)OC(C)C(=O)O</smiles><smiles>CC(O)C(=O)OCc1ccccc1</smiles><smiles>CC(OC(=O)C(C)O[Si](C)(C)C)C(=O)OCc1ccccc1</smiles>

In an oven-dried round-bottom flask, a suspension of L-lactide or D-lactide $(25 \mathrm{~g})$ in water $(100 \mathrm{~mL})$ was stirred for $4 \mathrm{~h}$ at $40^{\circ} \mathrm{C}$. The solvent was then evaporated under reduced pressure. The product 1 was obtained as colorless oil (28 g, 99\% yield). $\left.{ }^{1} \mathrm{H} \mathrm{NMR} \mathrm{(400MHz,} \mathrm{CDCl}_{3}\right): 5.19$ (q, J = 7.1 Hz, $1 \mathrm{H}$, $\left.\mathrm{CO}_{2} \mathrm{CH}\left(\mathrm{CH}_{3}\right) \mathrm{CO}_{2} \mathrm{H}\right), 4.36\left(\mathrm{q}, \mathrm{J}=7.1 \mathrm{~Hz}, 1 \mathrm{H}, \mathrm{HOCH}\left(\mathrm{CH}_{3}\right) \mathrm{CO}_{2}\right), 1.56(\mathrm{~d}, \mathrm{~J}=7.1 \mathrm{~Hz}, 3 \mathrm{H}$, $\left.\mathrm{CO}_{2} \mathrm{CH}\left(\mathrm{CH}_{3}\right) \mathrm{CO}_{2} \mathrm{H}\right), 1.47\left(\mathrm{~d}, \mathrm{~J}=7.1 \mathrm{~Hz}, 3 \mathrm{H}, \mathrm{HOCH}\left(\mathrm{CH}_{3}\right) \mathrm{CO}_{2}\right) \mathrm{ppm}$.

In an oven-dried Schlenk flask, 1 ( 28 g, 1 eq.) and triethylamine (34.9 g, 2 eq.) were dissolved in dry dichloromethane $(200 \mathrm{~mL})$. Benzyl bromide $(26.5 \mathrm{~g}, 0.9 \mathrm{eq}$.) was added dropwise to a stirred solution at $0^{\circ} \mathrm{C}$. The reaction mixture was then stirred overnight at room temperature. The reaction mixture was washed with saturated aqueous $\mathrm{NH}_{4} \mathrm{Cl}$, water and brine. The combined organic layer was dried over $\mathrm{MgSO} 4$, and the solvent was removed under reduced pressure. The crude product was purified via flash column chromatography using 1:1 hexane: ethyl acetate as eluent. The product 2 was obtained as colorless oil $\left(29.6 \mathrm{~g}, 68 \%\right.$ yield). ${ }^{1} \mathrm{H}$ NMR $\left(400 \mathrm{MHz}, \mathrm{CDCl}_{3}\right): 7.36(\mathrm{~m}, 5 \mathrm{H}, \mathrm{Ar}), 5.20(\mathrm{~m}, 3 \mathrm{H}$, $\left.\mathrm{CO}_{2} \mathrm{CH}\left(\mathrm{CH}_{3}\right) \mathrm{CO}_{2} \mathrm{CH}_{2} \mathrm{Ph}\right), 4.34\left(\mathrm{~m}, 1 \mathrm{H}, \mathrm{HOCH}\left(\mathrm{CH}_{3}\right) \mathrm{CO}_{2} \mathrm{CH}\left(\mathrm{CH}_{3}\right) \mathrm{CO}_{2} \mathrm{Ph}\right), 2.72$ (b, 1H, OH), 1.54 $\left(\mathrm{d}, \mathrm{J}=7.1 \mathrm{~Hz}, 3 \mathrm{H}, \mathrm{CO}_{2} \mathrm{CH}\left(\mathrm{CH}_{3}\right) \mathrm{CO}_{2} \mathrm{CH}_{2} \mathrm{Ph}\right), 1.43\left(\mathrm{~d}, \mathrm{~J}=7.1 \mathrm{~Hz}, 3 \mathrm{H}, \mathrm{HOCH}\left(\mathrm{CH}_{3}\right) \mathrm{CO}_{2}\right) \mathrm{ppm}$.

In an oven-dried round-bottom flask, 2 (29.6 g, 1 eq.) and tert-butyldimethylsilyl chloride (21.2 g, 1.2 eq.) and imidazole (15.9 g, 2 eq.) were dissolved in DMF $(150 \mathrm{~mL})$. The reaction mixture was then stirred overnight at room temperature. The reaction was quenched with saturated aqueous $\mathrm{NaHCO}_{3}$ and extracted with hexane. The combined organic layer was dried over MgSO4, and the solvent was removed under reduced pressure. The crude product was purified via flash column chromatography using 5:1 hexane: ethyl acetate as eluent. The product 3 was obtained as colorless oil (36.5 g, 85\% 
yield). ${ }^{1} \mathrm{H}$ NMR (400MHz, $\left.\mathrm{CDCl}_{3}\right): 7.35(\mathrm{~m}, 5 \mathrm{H}, \mathrm{Ar}), 5.16\left(\mathrm{~m}, 3 \mathrm{H}, \mathrm{CO}_{2} \mathrm{CH}\left(\mathrm{CH}_{3}\right) \mathrm{CO}_{2} \mathrm{CH}_{2} \mathrm{Ph}\right), 4.38$ $\left(\mathrm{q}, \quad \mathrm{J}=6.8 \mathrm{~Hz}, \quad 1 \mathrm{H}, \quad \operatorname{SiOCH}\left(\mathrm{CH}_{3}\right) \mathrm{CO}_{2} \mathrm{CH}\left(\mathrm{CH}_{3}\right) \mathrm{CO}_{2} \mathrm{Ph}\right), 1.52(\mathrm{~d}, \quad \mathrm{~J}=7.1 \mathrm{~Hz}, 3 \mathrm{H}$, $\left.\mathrm{CO}_{2} \mathrm{CH}\left(\mathrm{CH}_{3}\right) \mathrm{CO}_{2} \mathrm{CH}_{2} \mathrm{Ph}\right), 1.41\left(\mathrm{~d}, \mathrm{~J}=7.1 \mathrm{~Hz}, 3 \mathrm{H}, \mathrm{SiOCH}\left(\mathrm{CH}_{3}\right) \mathrm{CO}_{2}\right), 0.90\left(\mathrm{~s}, 9 \mathrm{H},\left(\mathrm{CH}_{3}\right)_{3} \mathrm{CSi}\right), 0.10$ $\left(\mathrm{s}, 3 \mathrm{H},\left(\mathrm{CH}_{3}\right)_{2} \mathrm{Si}\right), 0.08\left(\mathrm{~s}, 3 \mathrm{H},\left(\mathrm{CH}_{3}\right)_{2} \mathrm{Si}\right) \mathrm{ppm}$.

\section{Synthesis of TBDMS-[DLA $\left.\mathbf{3 2}_{32}-\mathrm{XLA} \mathrm{A}_{8}\right]-\mathrm{Bn}(\mathrm{X}=\mathrm{D}$ or $\mathrm{L}$ or $\mathrm{D} / \mathrm{L})$}
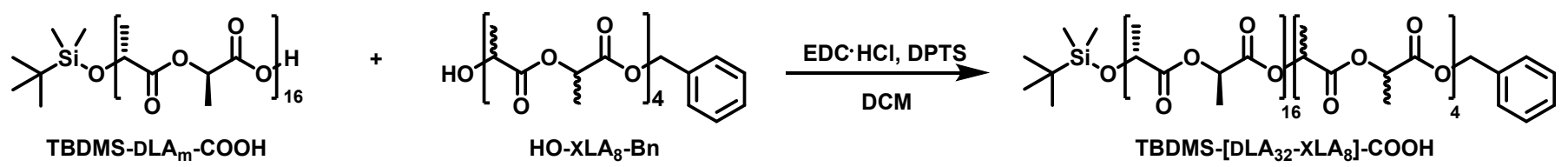

In an oven-dried Schlenk flask, TBDMS-DLA ${ }_{32}-\mathrm{COOH}(0.1 \mathrm{~g}, 1$ eq. $)$ and HO-XLA $-\mathrm{Bn}(0.042 \mathrm{~g}, 1.5$ eq.) were dissolved in dry dichloromethane $(10 \mathrm{~mL})$. To the solution, DPTS $(2 \mathrm{mg}, 0.2 \mathrm{eq}$.) and $\mathrm{EDC} \cdot \mathrm{HCl}$, (0.12 g, 1.5 eq.) were added. The reaction mixture was stirred overnight at room temperature. The reaction mixture was washed with water and brine. The combined organic layer was dried over $\mathrm{MgSO} 4$, and the solvent was removed under reduced pressure. The crude product was washed with 7:3 hexane:ethyl acetate to remove unreacted $\mathrm{HO}-\mathrm{XLA}_{8}-\mathrm{Bn}$ and purified via flash column chromatography using 2:8 hexane:ethyl acetate as eluent. The product was obtained as a white solid $(0.091 \mathrm{~g}$, yield $71 \%) .{ }^{1} \mathrm{H}$ NMR $\left(400 \mathrm{MHz}, \mathrm{CDCl}_{3}\right): 7.35(\mathrm{~m}, 5 \mathrm{H}, \mathrm{Ar}), 5.16(\mathrm{~m}, 21 \mathrm{H}$, $\left.\mathrm{CO}_{2}\left[\mathrm{CH}\left(\mathrm{CH}_{3}\right) \mathrm{CO}_{2}\right] \mathrm{CH}_{2} \mathrm{Ph}\right), 4.39\left(\mathrm{q}, \mathrm{J}=6.8 \mathrm{~Hz}, 1 \mathrm{H}, \mathrm{SiOCH}\left(\mathrm{CH}_{3}\right) \mathrm{CO}_{2}\right), 1.54(\mathrm{~m}, \mathrm{~J}=7.1 \mathrm{~Hz}, 120 \mathrm{H}$, $\left.\mathrm{CO}_{2} \mathrm{CH}\left(\mathrm{CH}_{3}\right) \mathrm{CO}_{2}\right), 0.90\left(\mathrm{~s}, 9 \mathrm{H},\left(\mathrm{CH}_{3}\right)_{3} \mathrm{CSi}\right), 0.10\left(\mathrm{~s}, 3 \mathrm{H},\left(\mathrm{CH}_{3}\right)_{2} \mathrm{Si}\right), 0.08\left(\mathrm{~s}, 3 \mathrm{H},\left(\mathrm{CH}_{3}\right)_{2} \mathrm{Si}\right) \mathrm{ppm}$.

\section{Crystallization-Driven Self-Assembly ${ }^{2}$}

$\mathrm{BCP}$ was added to $1 \mathrm{~mL}$ of ethanol in a $4 \mathrm{~mL}$ vial. The samples were heated in oil bath at $75{ }^{\circ} \mathrm{C}$, followed by a slow cooling and equilibration at $25{ }^{\circ} \mathrm{C}$ without perturbation for $24 \mathrm{~h}$. The resulting solution was diluted with water $(0.1 \mathrm{mg} / \mathrm{mL})$ and equilibrated at $25^{\circ} \mathrm{C}$ for $4 \mathrm{~h}$. The diluted solution was studied by TEM, AFM.

$\left[\mathrm{DLA}_{32}-\mathrm{XLA}_{8}\right]-b-\mathrm{PEG}_{\sim 45}(0.5 \mathrm{mg})$ and $\mathrm{LLA}_{40}-b-\mathrm{PEG}_{\sim 45}(0.5 \mathrm{mg})$ were mixed and added to $1 \mathrm{~mL}$ of ethanol in a $4 \mathrm{~mL}$ vial. The samples were heated in oil bath at $75^{\circ} \mathrm{C}$, followed by a slow cooling and equilibration at $25^{\circ} \mathrm{C}$ without perturbation for $24 \mathrm{~h}$. The resulting solution was diluted with water $(0.1$ $\mathrm{mg} / \mathrm{mL}$ ) and equilibrated at $25^{\circ} \mathrm{C}$ for $4 \mathrm{~h}$. The diluted solution was studied by TEM, AFM.

$\mathrm{DLA}_{\mathrm{n}}-b-\mathrm{PEG}_{\sim 45}(0.5 \mathrm{mg})$ and $\mathrm{LLA}_{\mathrm{m}}-b-\mathrm{PEG}_{\sim 45}$ (equivalent molar ratio) $(\mathrm{n} \geq \mathrm{m})$ were mixed and added to $1 \mathrm{~mL}$ of ethanol in a $4 \mathrm{~mL}$ vial. The samples were heated in oil bath at $75^{\circ} \mathrm{C}$, followed by a slow cooling and equilibration at $25{ }^{\circ} \mathrm{C}$ without perturbation for $24 \mathrm{~h}$. The resulting solution was diluted with water $(0.1 \mathrm{mg} / \mathrm{mL})$ and equilibrated at $25^{\circ} \mathrm{C}$ for $4 \mathrm{~h}$. The diluted solution was studied by TEM, AFM. 

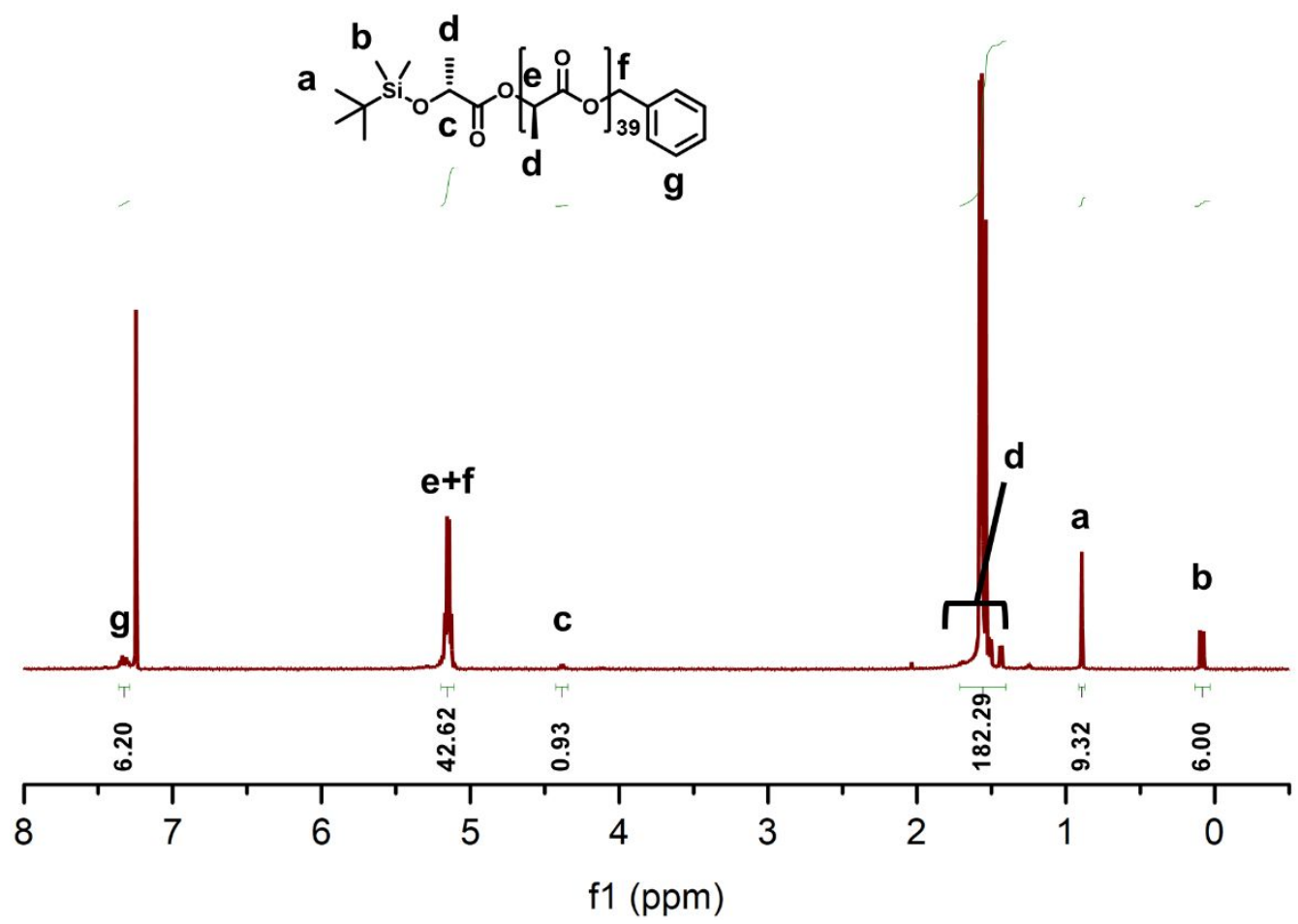

Figure S1. ${ }^{1} \mathrm{H}$ NMR (400 MHz, $\left.\mathrm{CDCl}_{3}\right)$ spectra of [DLA 40$]$.
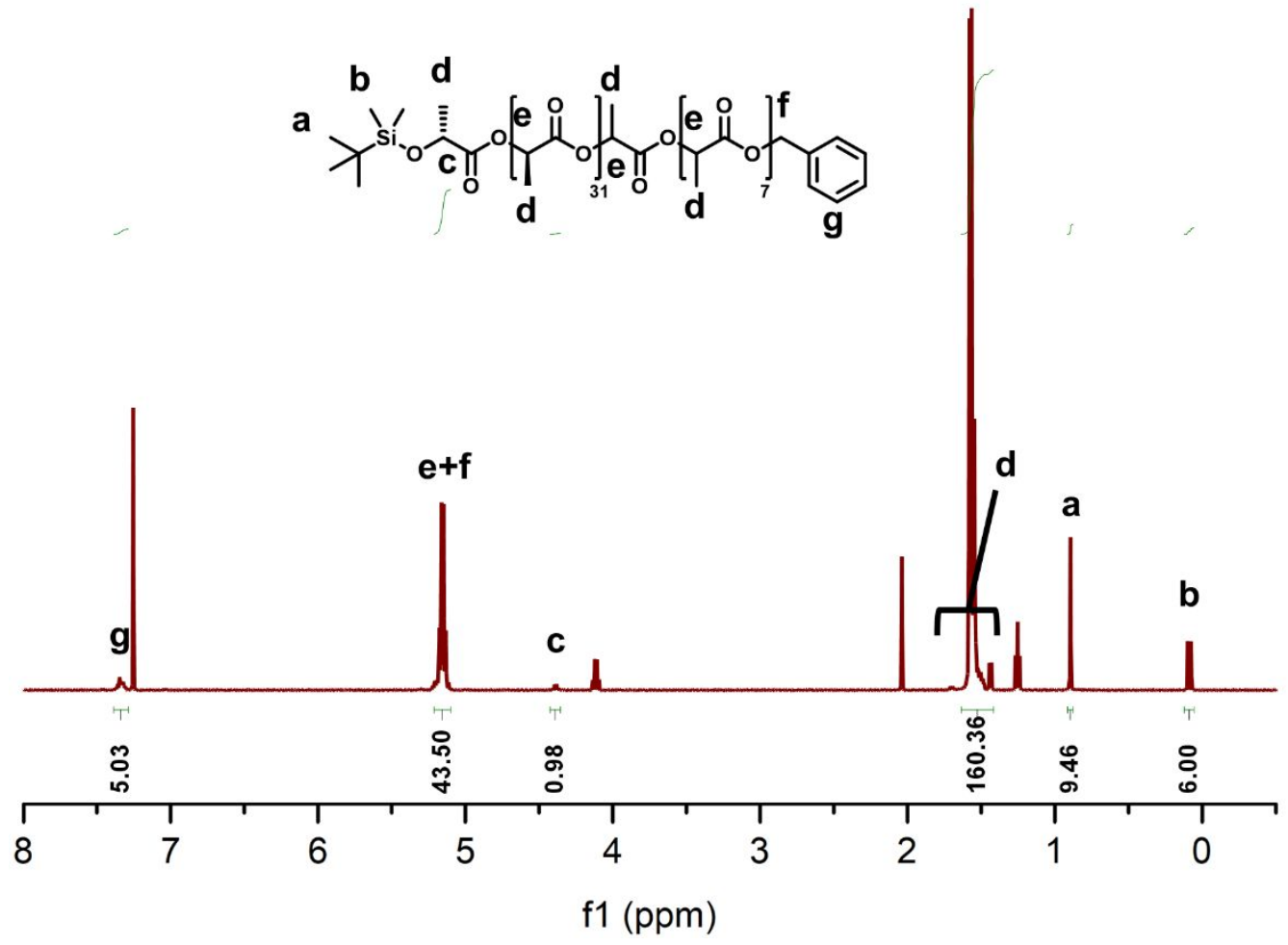

Figure S2. ${ }^{1} \mathrm{H}$ NMR $\left(400 \mathrm{MHz}, \mathrm{CDCl}_{3}\right)$ spectra of $\left[\mathrm{DLA}_{32}-\mathrm{D} / \mathrm{LLA}_{8}\right]$. 


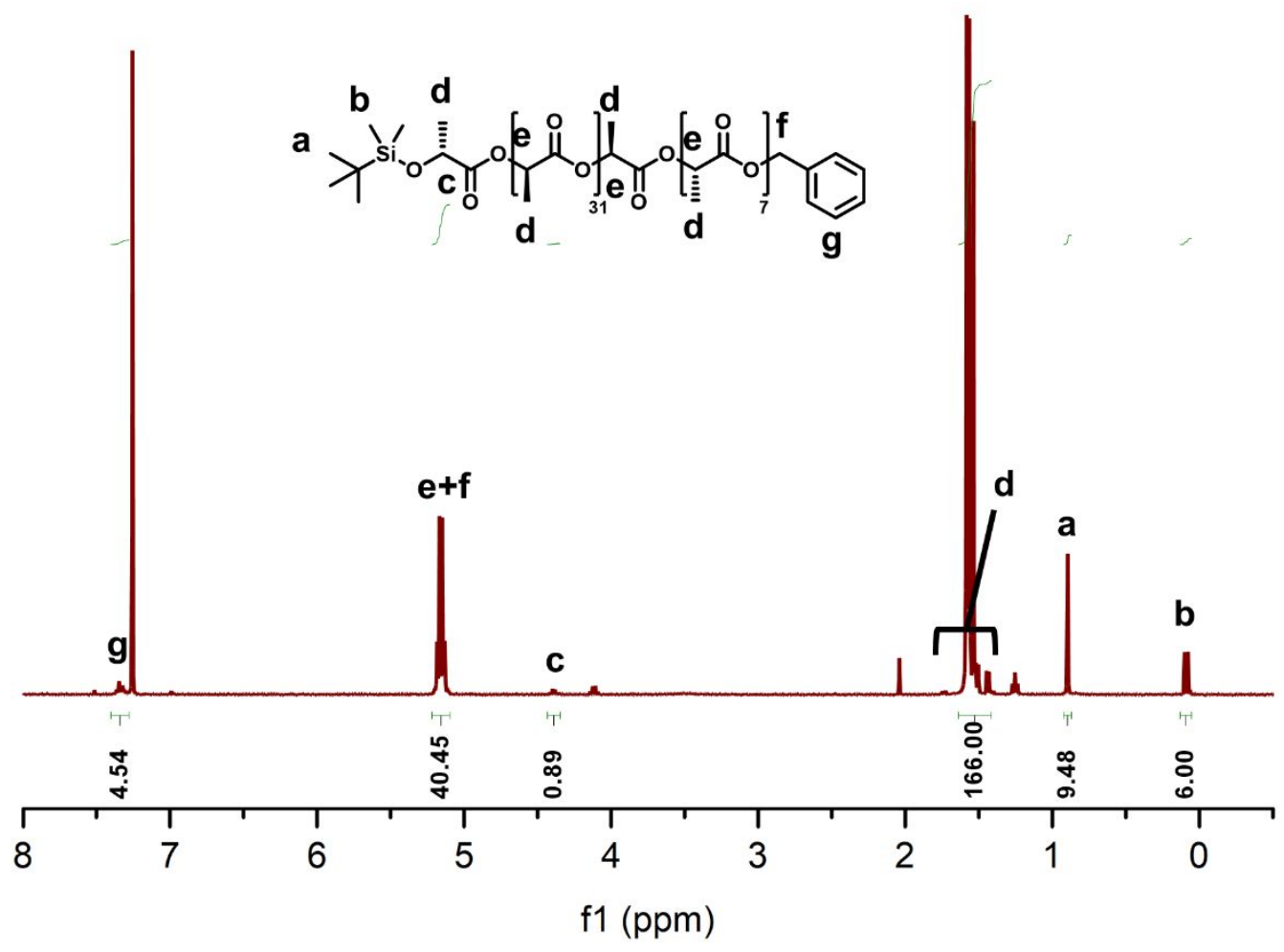

Figure S3. ${ }^{1} \mathrm{H}$ NMR $\left(400 \mathrm{MHz}, \mathrm{CDCl}_{3}\right)$ spectra of $\left[\mathrm{DLA}_{32}-\mathrm{LLA}_{8}\right]$.

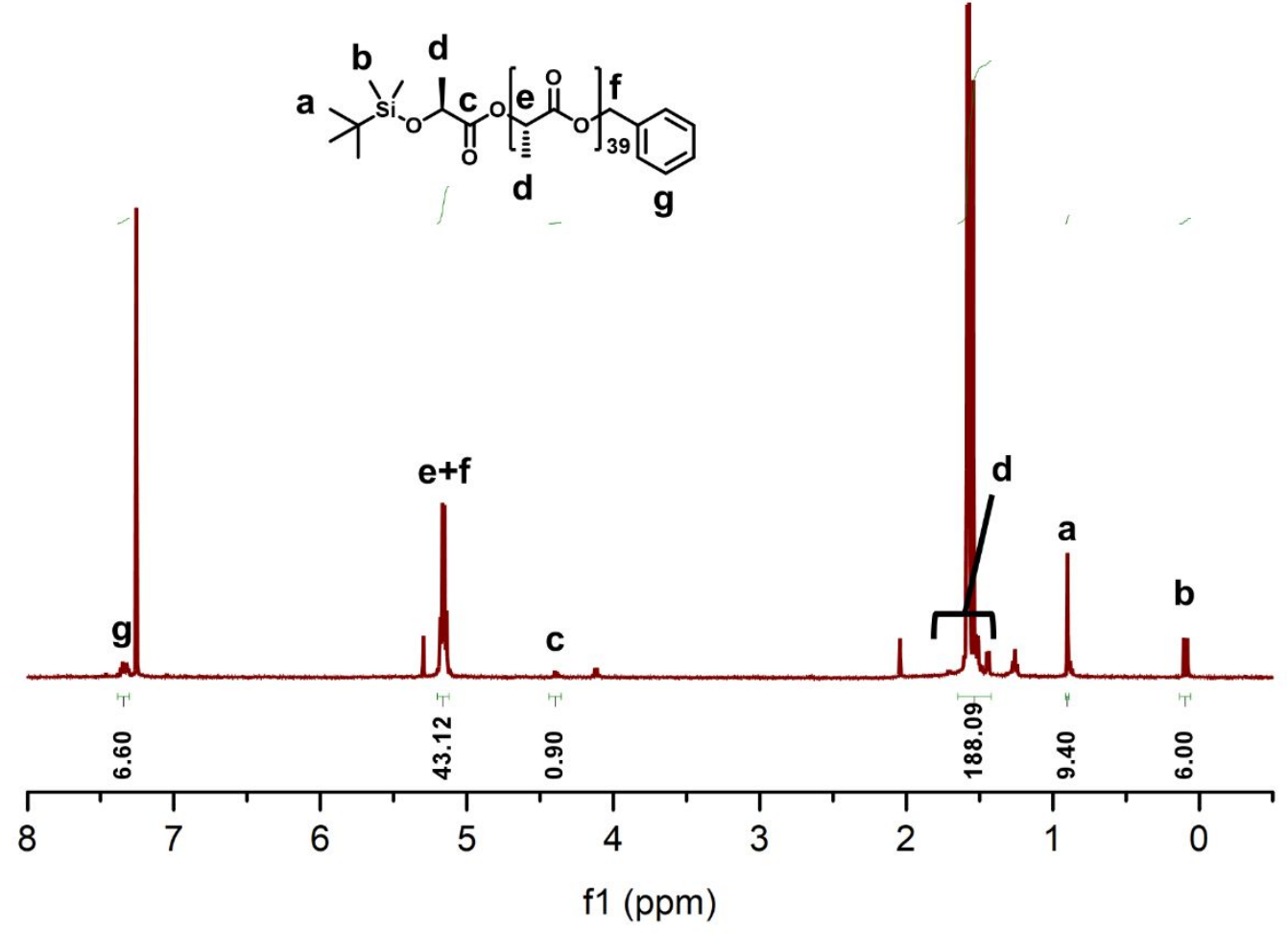

Figure S4. ${ }^{1} \mathrm{H}$ NMR $\left(400 \mathrm{MHz}, \mathrm{CDCl}_{3}\right)$ spectra of $\left[\mathrm{LLA}_{40}\right]$. 


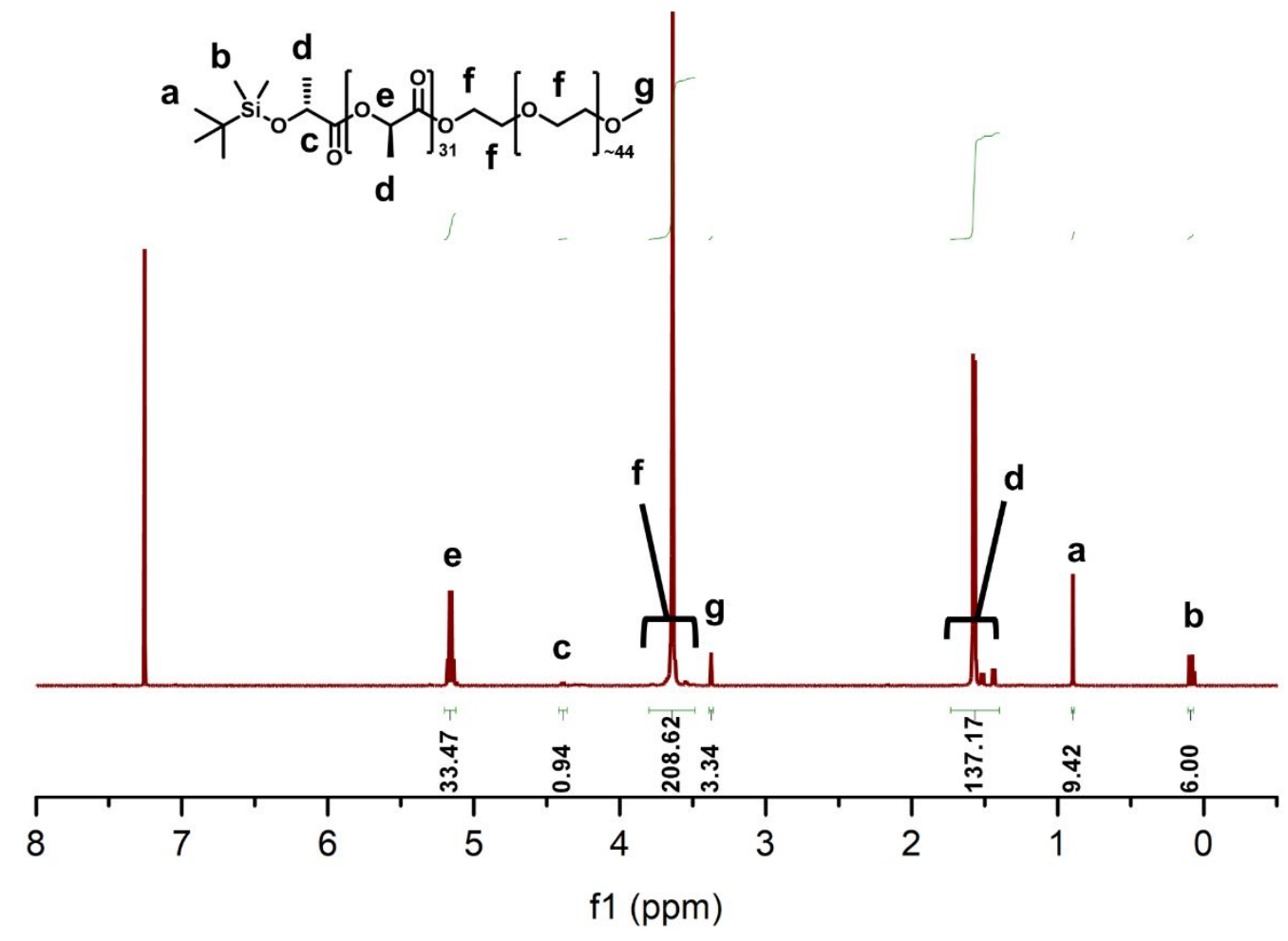

Figure S5. ${ }^{1} \mathrm{H}$ NMR $\left(400 \mathrm{MHz}, \mathrm{CDCl}_{3}\right)$ spectra of $\left[\mathrm{DLA}_{32}\right]$ - $b$-PEG.

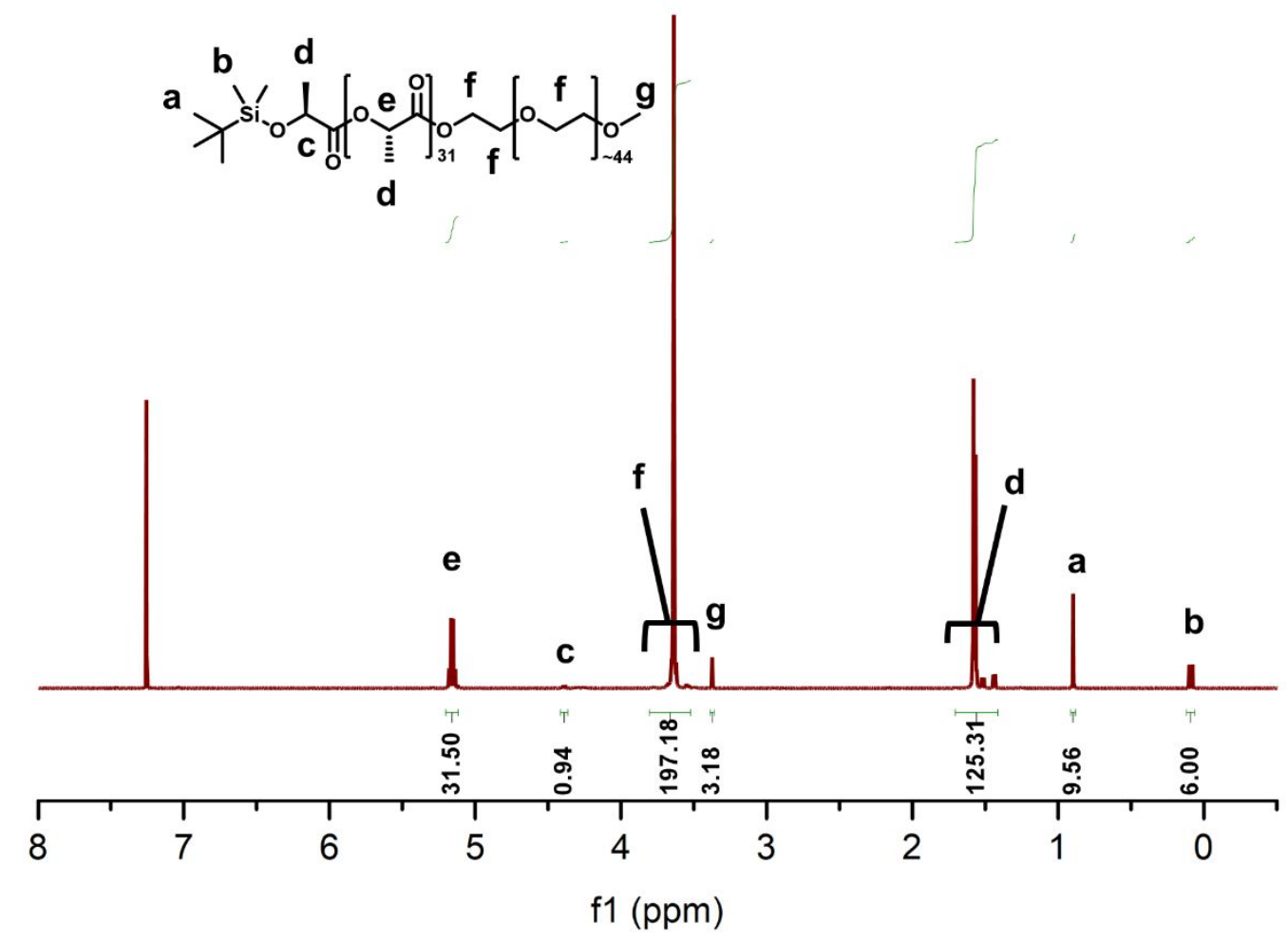

Figure S6. ${ }^{1} \mathrm{H}$ NMR $\left(400 \mathrm{MHz}, \mathrm{CDCl}_{3}\right)$ spectra of [LLA 32$]-b$-PEG. 


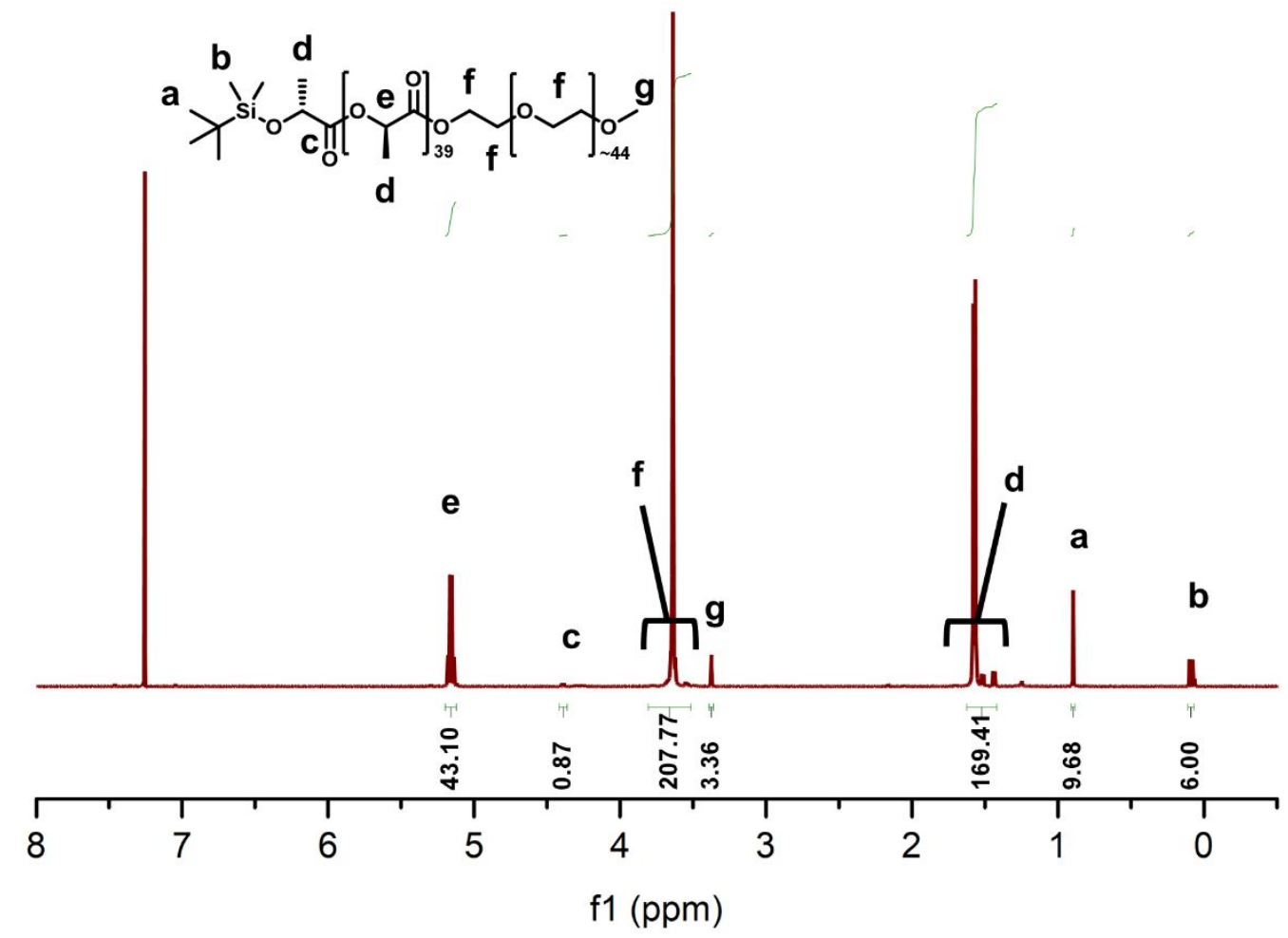

Figure S7. ${ }^{1} \mathrm{H}$ NMR $\left(400 \mathrm{MHz}, \mathrm{CDCl}_{3}\right)$ spectra of $\left[\mathrm{DLA}_{40}\right]$ - $b$-PEG.

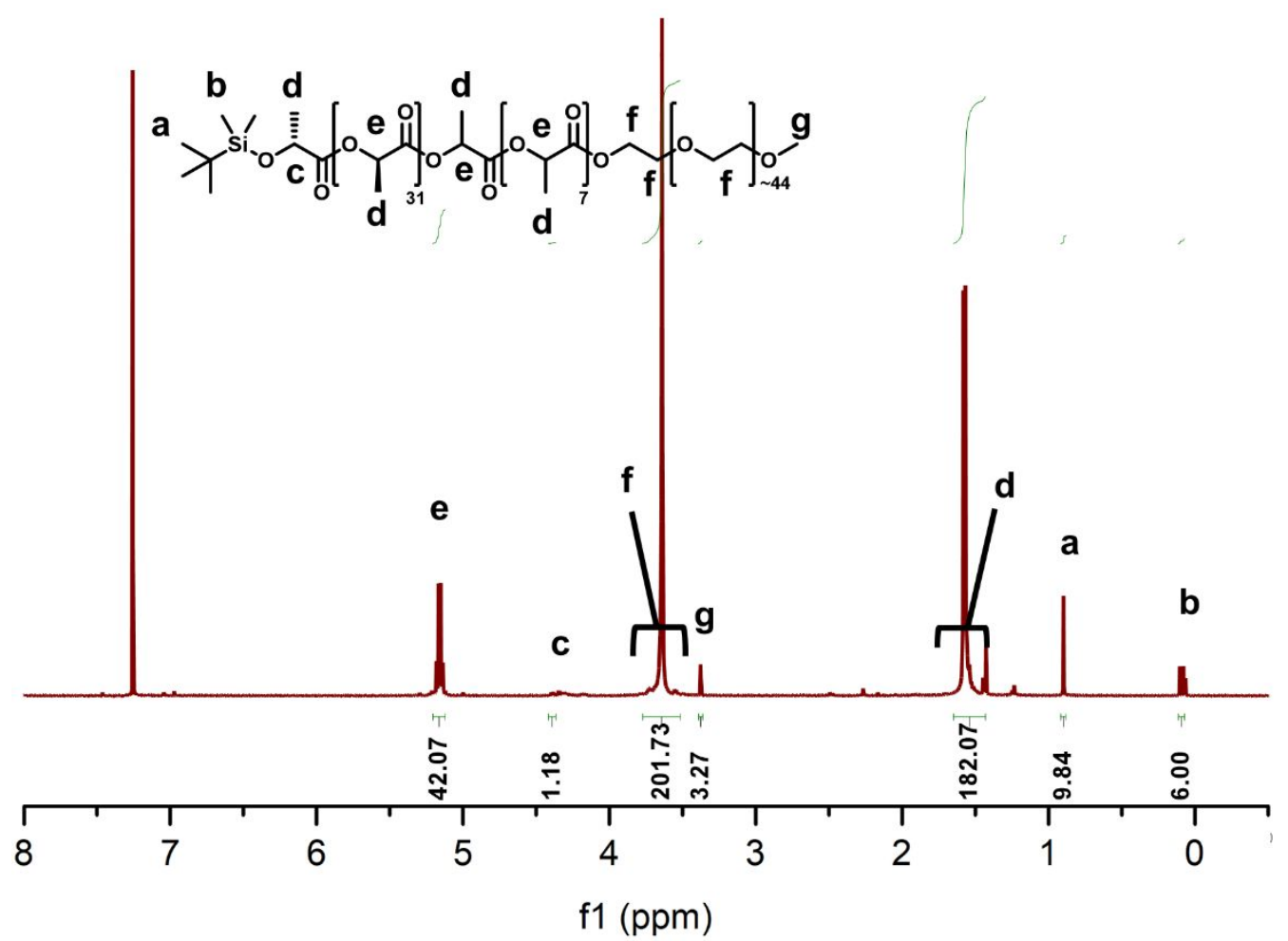

Figure S8. ${ }^{1} \mathrm{H}$ NMR $\left(400 \mathrm{MHz}, \mathrm{CDCl}_{3}\right)$ spectra of $\left[\mathrm{DLA}_{32}\right.$-D/LLA 8 - $b$-PEG. 


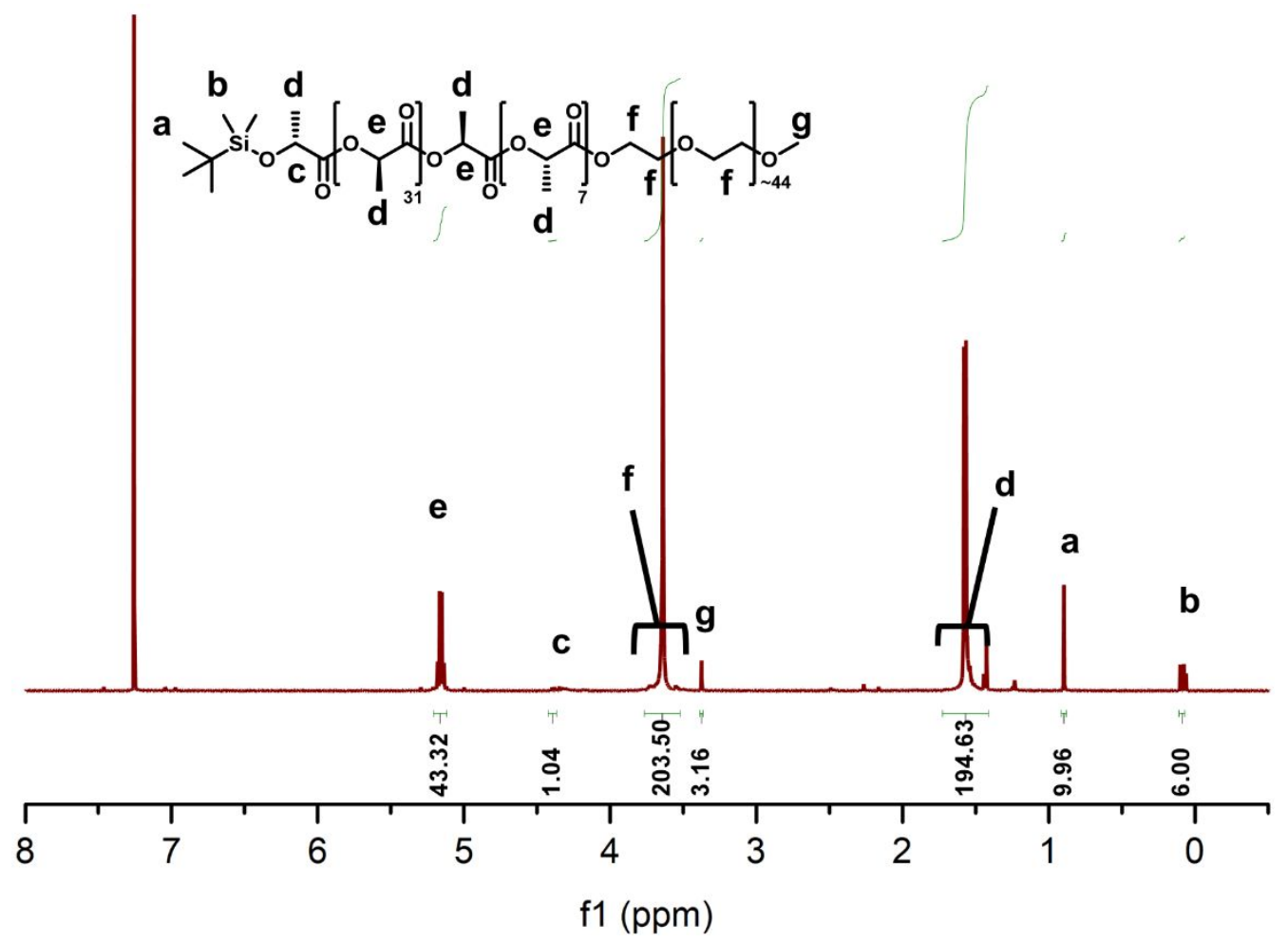

Figure S9. ${ }^{1} \mathrm{H}$ NMR $\left(400 \mathrm{MHz}, \mathrm{CDCl}_{3}\right)$ spectra of $\left[\mathrm{DLA}_{32}\right.$-LLA 8 - $b$-PEG.

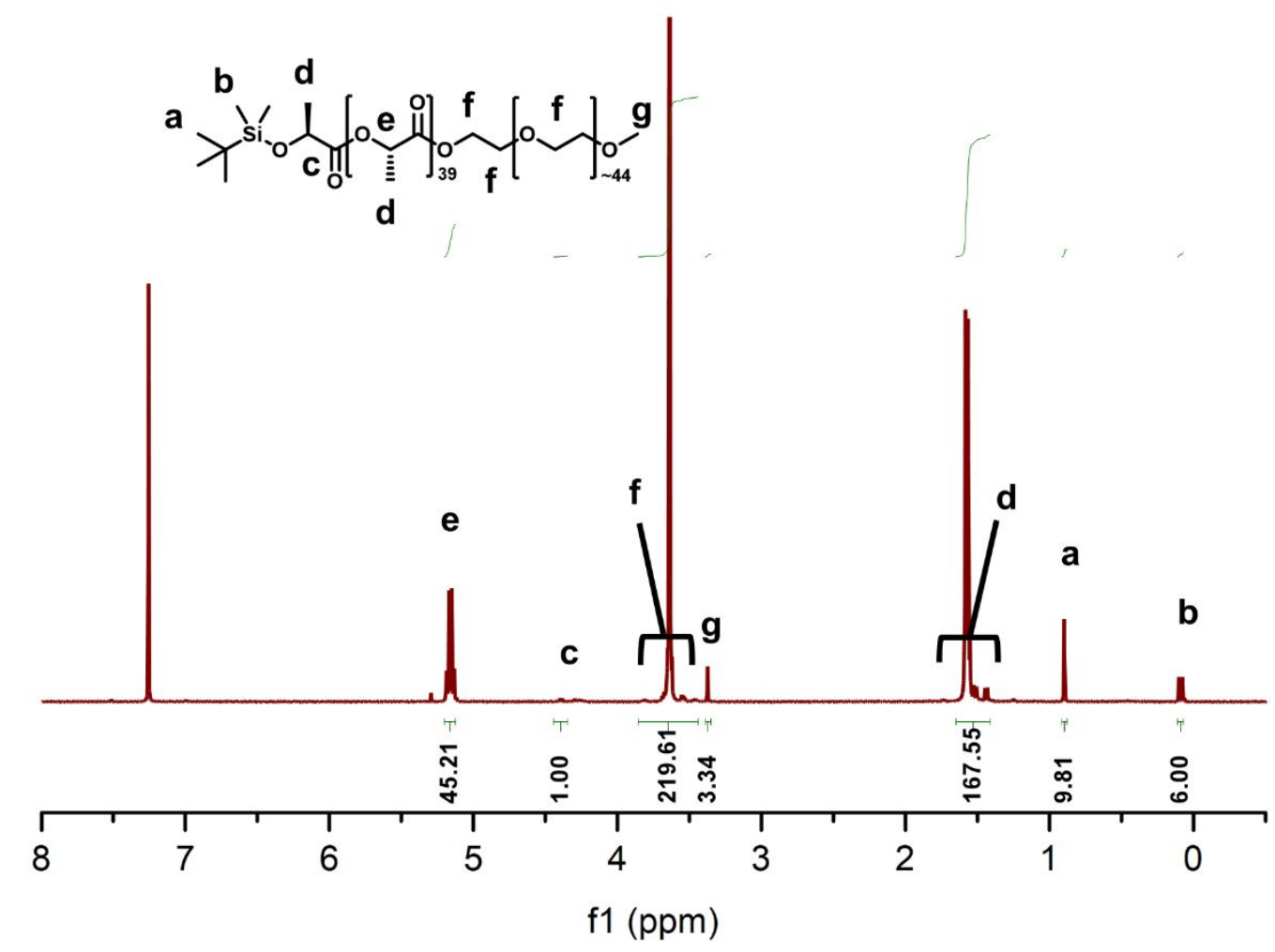

Figure S10. ${ }^{1} \mathrm{H}$ NMR $\left(400 \mathrm{MHz}, \mathrm{CDCl}_{3}\right)$ spectra of $\left[\mathrm{LLA}_{40}\right]-b$-PEG. 


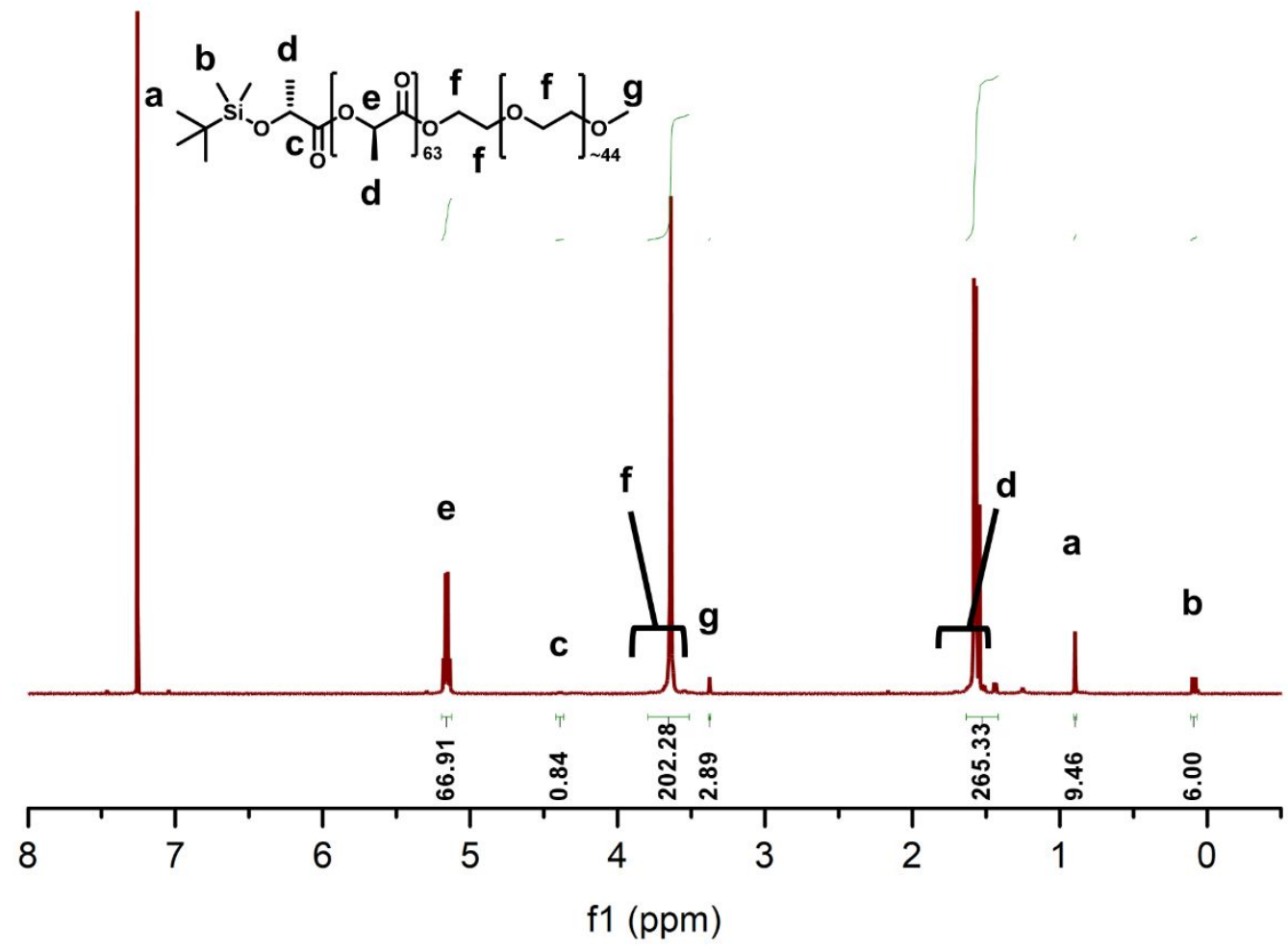

Figure S11. ${ }^{1} \mathrm{H}$ NMR $\left(400 \mathrm{MHz}, \mathrm{CDCl}_{3}\right.$ ) spectra of [DLA 64 - $b$-PEG.

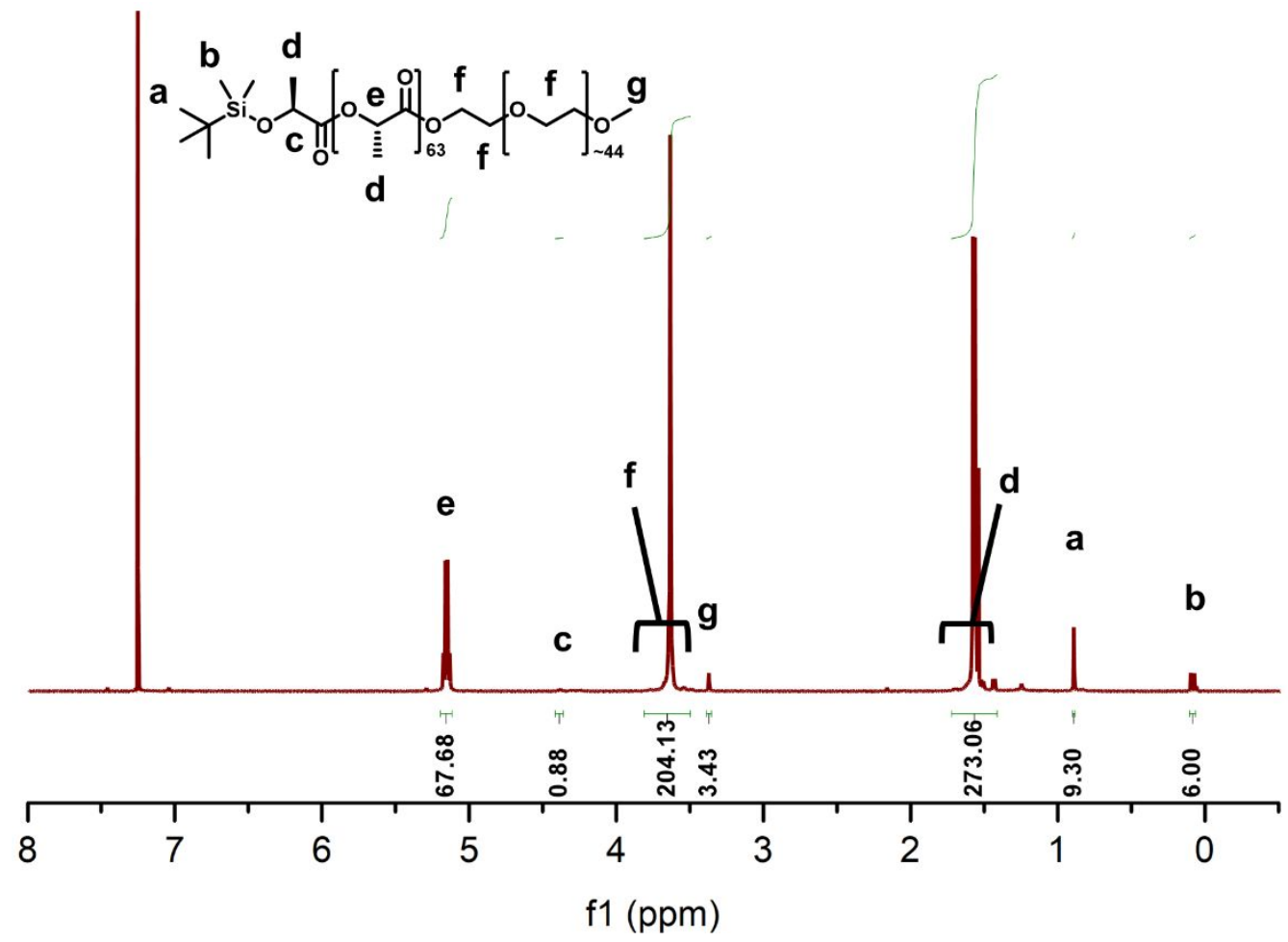

Figure S12. ${ }^{1} \mathrm{H}$ NMR $\left(400 \mathrm{MHz}, \mathrm{CDCl}_{3}\right)$ spectra of [LLA 64 - $b$-PEG. 


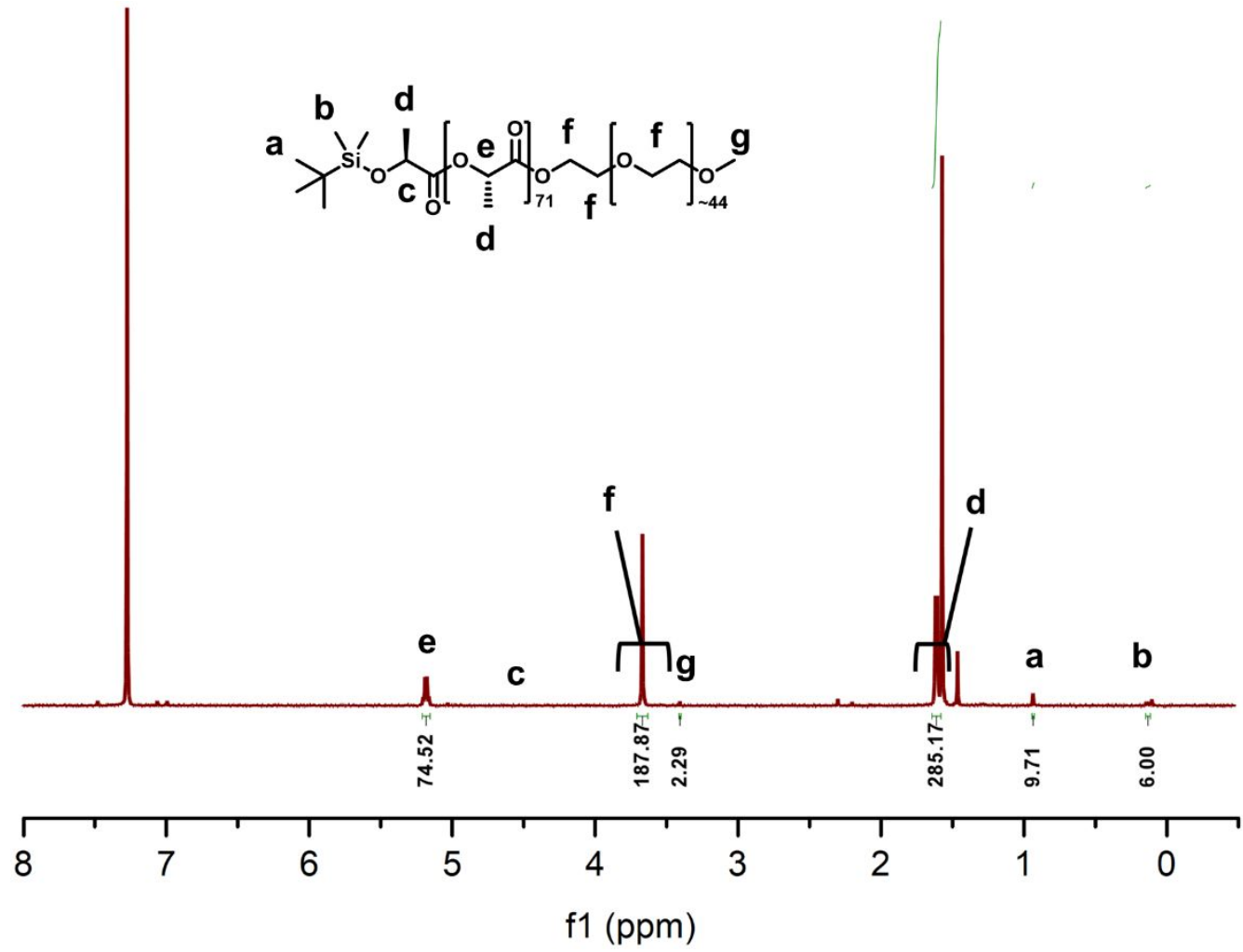

Figure S13. ${ }^{1} \mathrm{H}$ NMR $\left(400 \mathrm{MHz}, \mathrm{CDCl}_{3}\right)$ spectra of $\left[\mathrm{DLA}_{72}\right]-b$-PEG. 


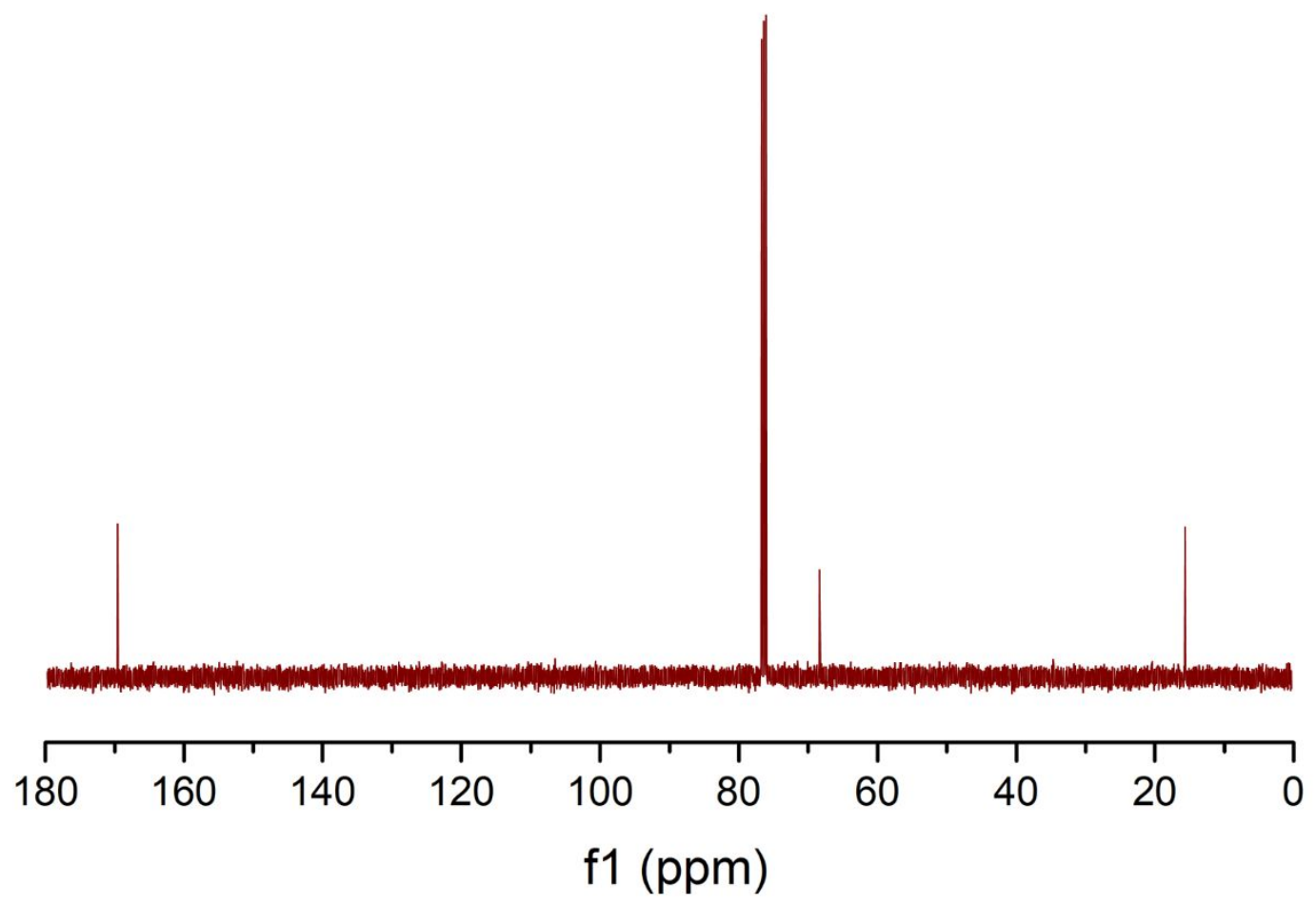

Figure S14. ${ }^{13} \mathrm{C}$ NMR $\left(400 \mathrm{MHz}, \mathrm{CDCl}_{3}\right)$ spectra of [DLA 40$]$.

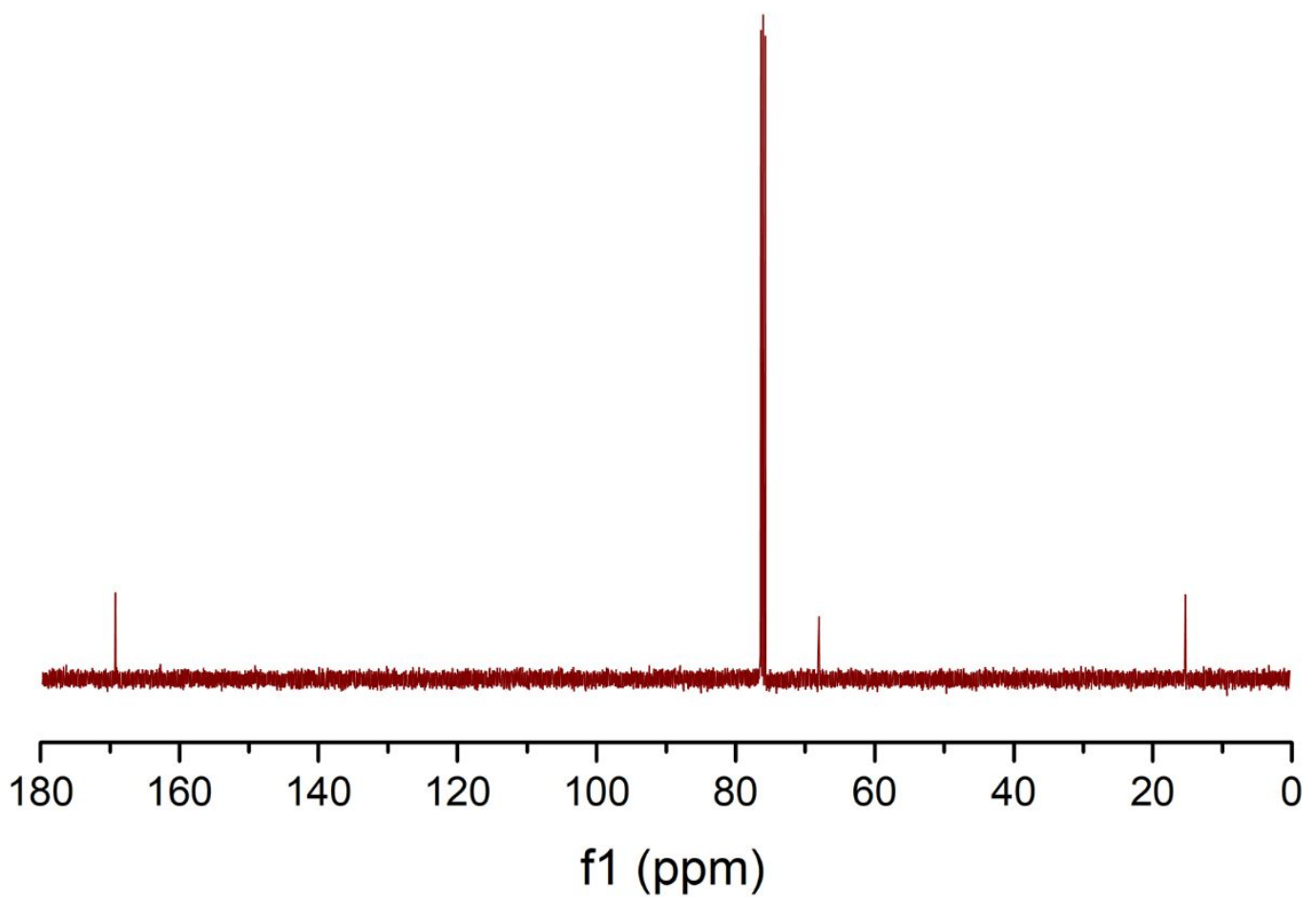

Figure S15. ${ }^{13} \mathrm{C}$ NMR $\left(400 \mathrm{MHz}, \mathrm{CDCl}_{3}\right)$ spectra of [DLA 32 -D/LLA 8 ]. 


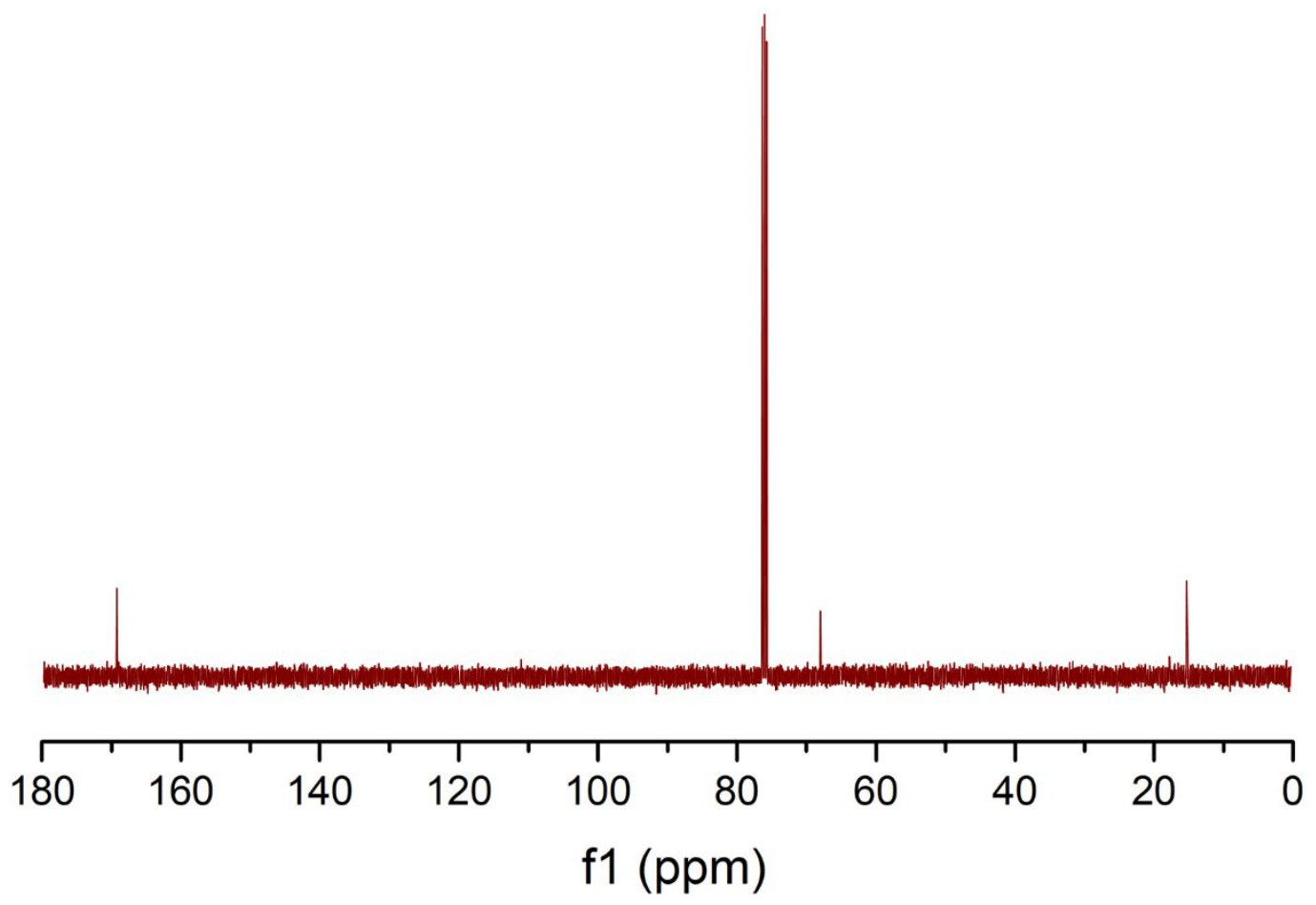

Figure S16. ${ }^{13} \mathrm{C}$ NMR $\left(400 \mathrm{MHz}, \mathrm{CDCl}_{3}\right)$ spectra of $\left[\mathrm{DLA}_{32}-\mathrm{LLA}_{8}\right]$.

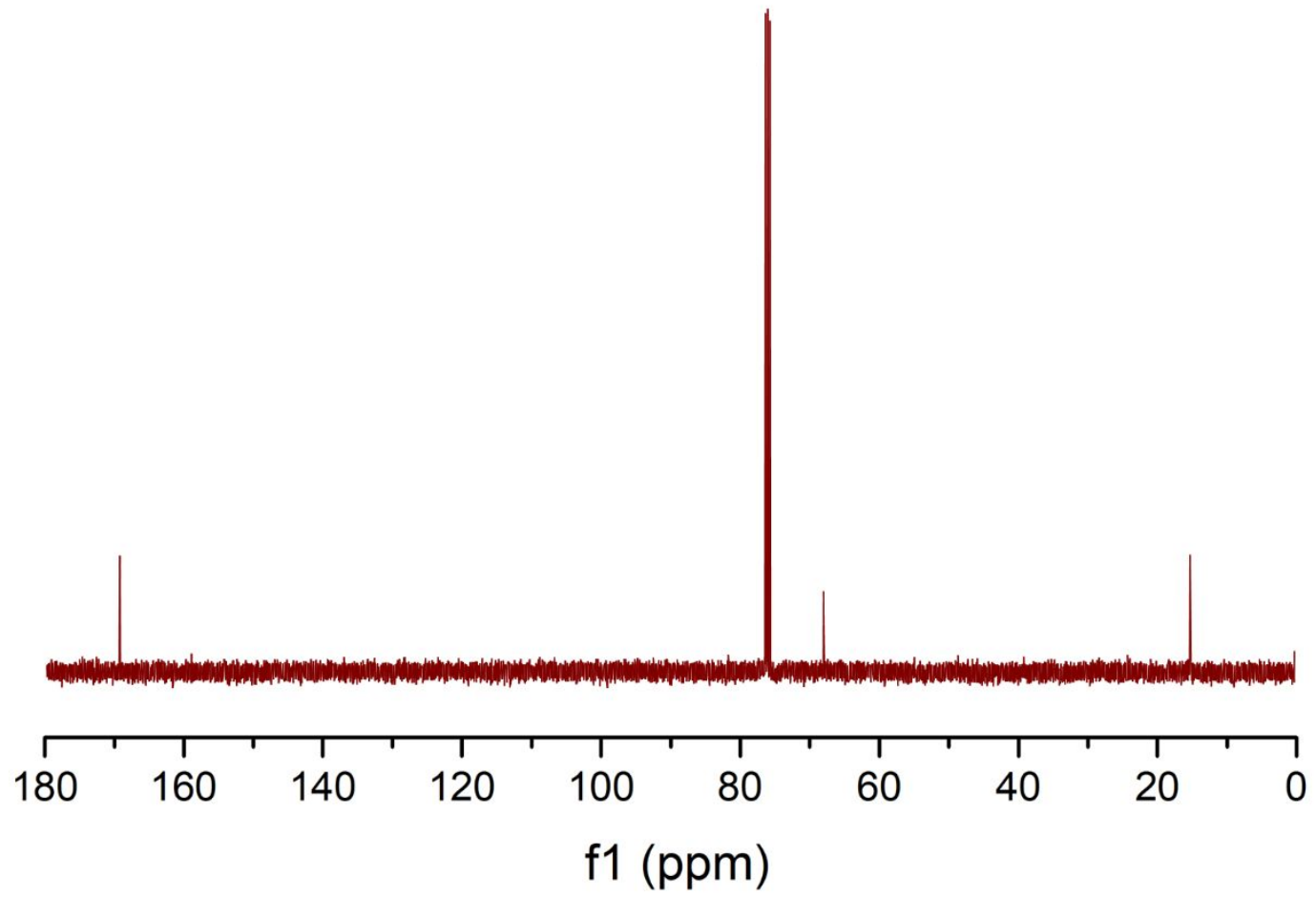

Figure S17. ${ }^{13} \mathrm{C}$ NMR $\left(400 \mathrm{MHz}, \mathrm{CDCl}_{3}\right)$ spectra of [LLA 40 ]. 
a

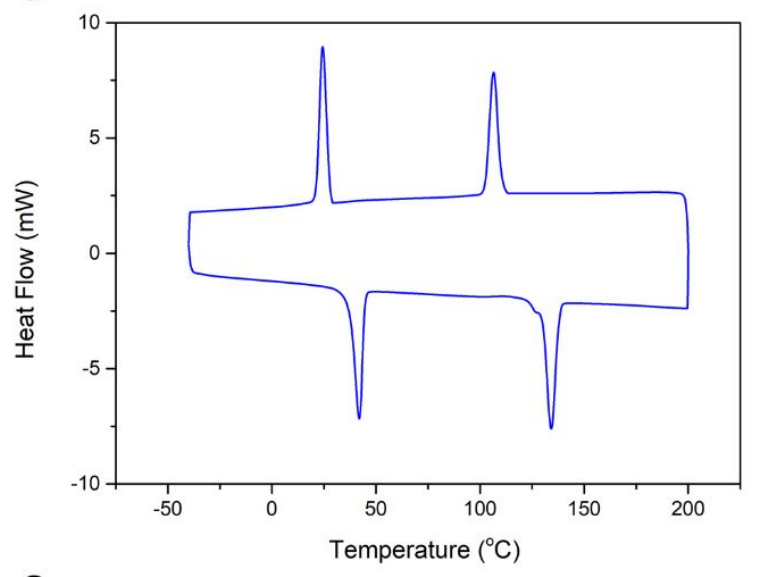

C

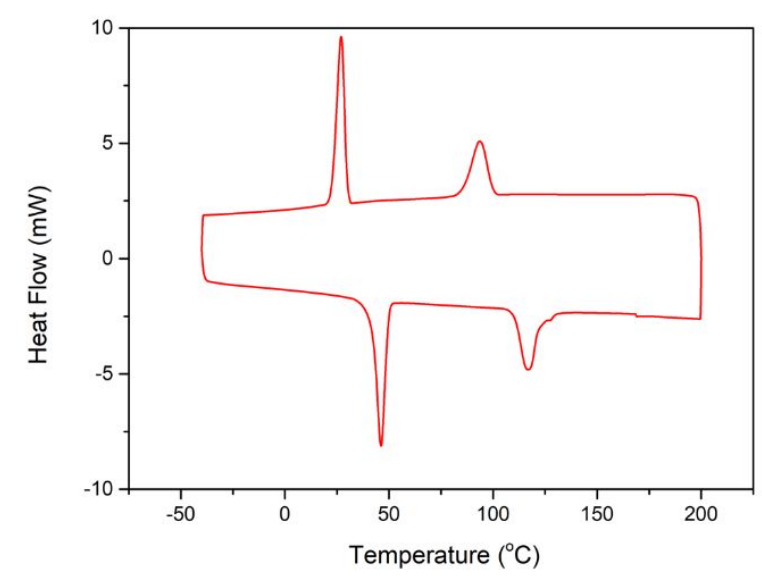

b

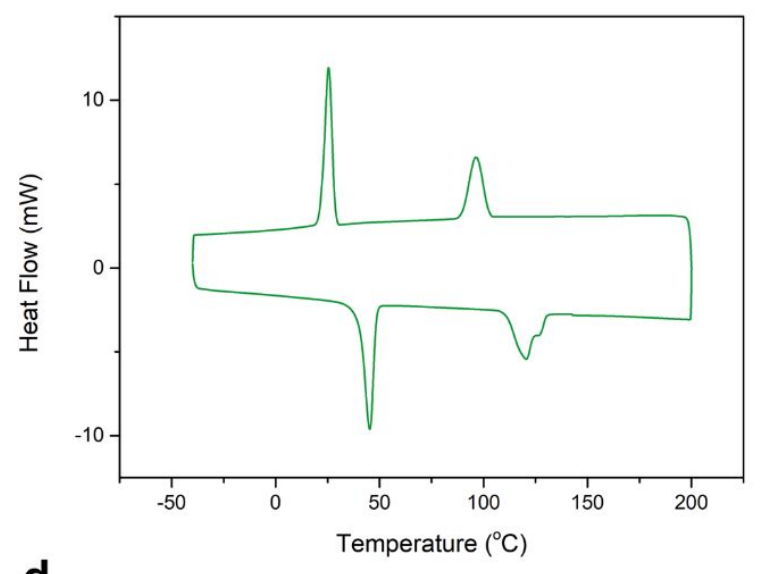

d

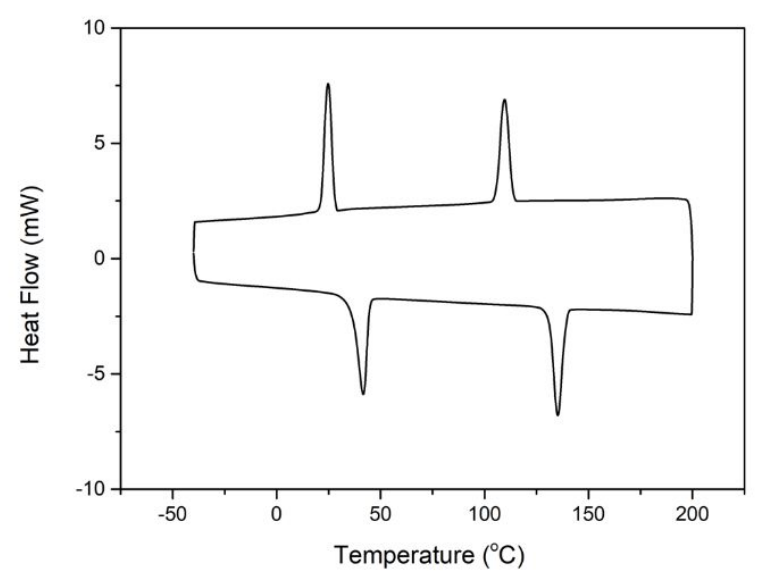

Figure S18. DSC traces (second scan, ramp rate $=10{ }^{\circ} \mathrm{C} \mathrm{min}{ }^{-1}$ ) for block copolymers (a) [DLA 40$]-b$ PEG (blue, $T_{\mathrm{m}}: 134.8^{\circ} \mathrm{C}, T_{\mathrm{c}}: 107.4^{\circ} \mathrm{C}$ ), (b) [DLA $32^{-\mathrm{D} / \mathrm{LLA}} 8$ ]- $b$-PEG (green, $T_{\mathrm{m}}: 120.2^{\circ} \mathrm{C}, T_{\mathrm{c}}: 96.1^{\circ} \mathrm{C}$ ), (c) $\left[\mathrm{DLA}_{32}-\mathrm{LLA}_{8}\right]-b-\mathrm{PEG}\left(\mathrm{red}, T_{\mathrm{m}}: 117.0^{\circ} \mathrm{C}, T_{\mathrm{c}}: 93.3^{\circ} \mathrm{C}\right.$ ), (d) [LLA 40$]-b-\mathrm{PEG}\left(\right.$ black, $T_{\mathrm{m}}: 135.2^{\circ} \mathrm{C}, T_{\mathrm{c}}$ : $\left.109.1^{\circ} \mathrm{C}\right)$. 
a

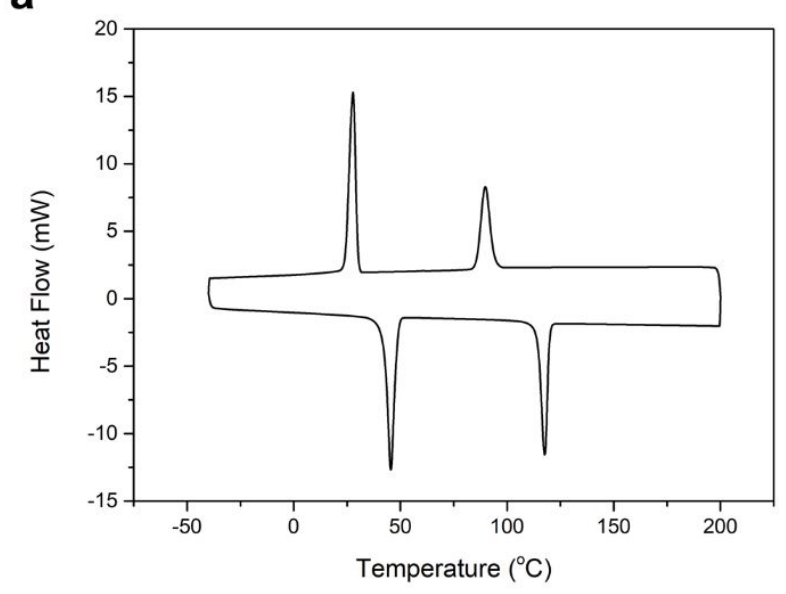

C

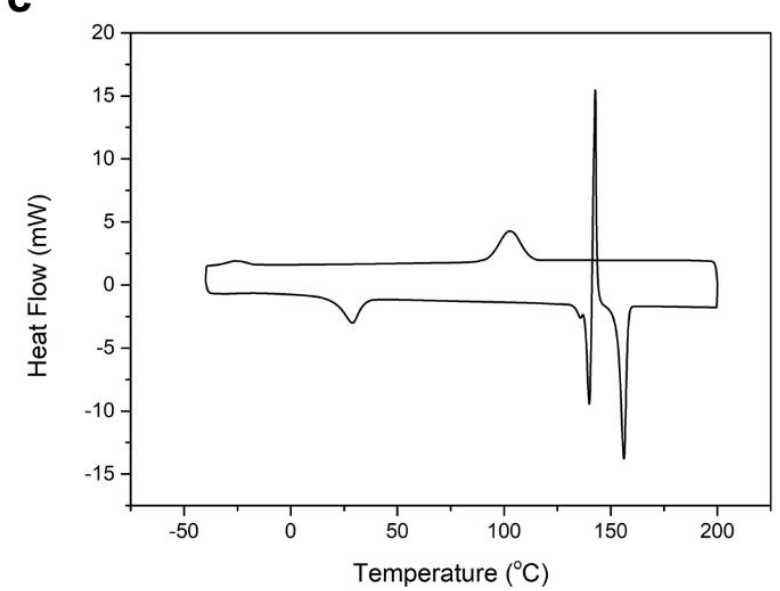

e

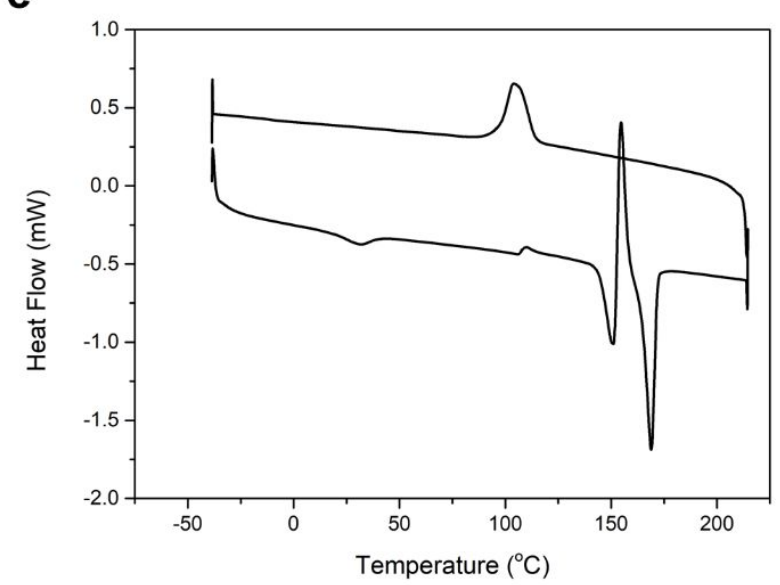

b

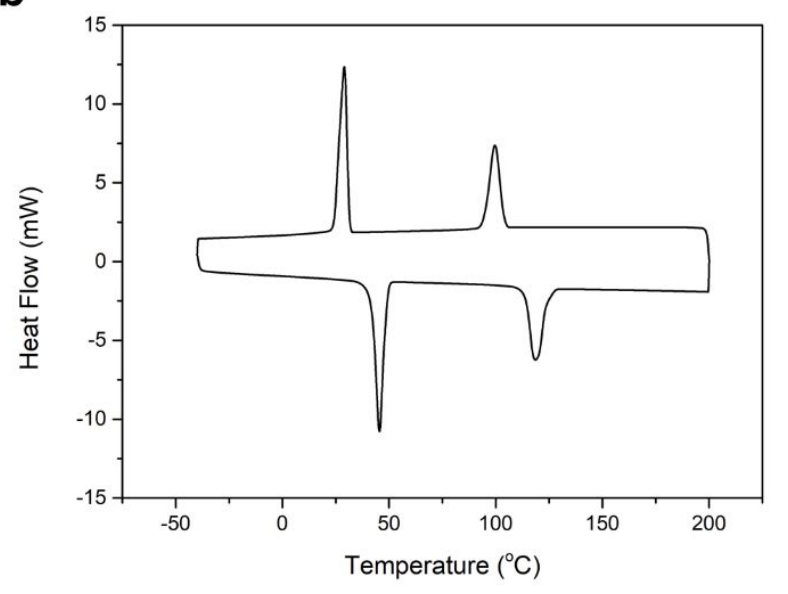

d

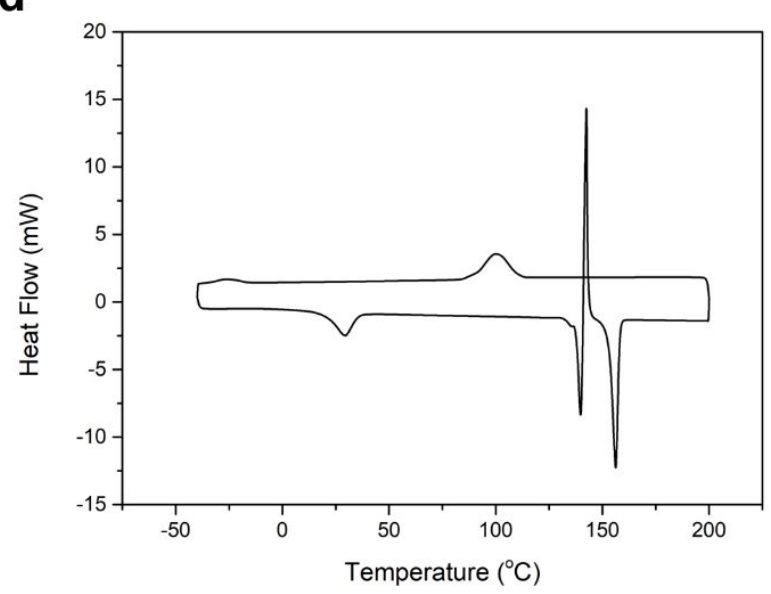

Figure S19. DSC traces (second scan, ramp rate $=10^{\circ} \mathrm{C} \mathrm{min}^{-1}$ ) for block copolymers (a) [DLA 32 - $b$ PEG $\left(T_{\mathrm{m}}: 117.5^{\circ} \mathrm{C}, T_{\mathrm{c}}: 89.9^{\circ} \mathrm{C}\right)$, (b) $\left[\mathrm{LLA}_{32}\right]-b-\mathrm{PEG}\left(T_{\mathrm{m}}: 118.7^{\circ} \mathrm{C}, T_{\mathrm{c}}: 99.6^{\circ} \mathrm{C}\right)$, (c) [DLA 64$]-b-\mathrm{PEG}$ $\left(T_{\mathrm{m}}: 156.1^{\circ} \mathrm{C}, T_{\mathrm{c}}: 101.6^{\circ} \mathrm{C}\right)$, (d) $\left[\mathrm{LLA}_{64}\right]-b-\mathrm{PEG}\left(T_{\mathrm{m}}: 155.2^{\circ} \mathrm{C}, T_{\mathrm{c}}: 102.8^{\circ} \mathrm{C}\right),(\mathrm{e})\left[\mathrm{DLA}_{72}\right]-b-\mathrm{PEG}\left(T_{\mathrm{m}}\right.$ $\left.: 170.4^{\circ} \mathrm{C}, T_{\mathrm{c}}: 109.7^{\circ} \mathrm{C}\right)$. 

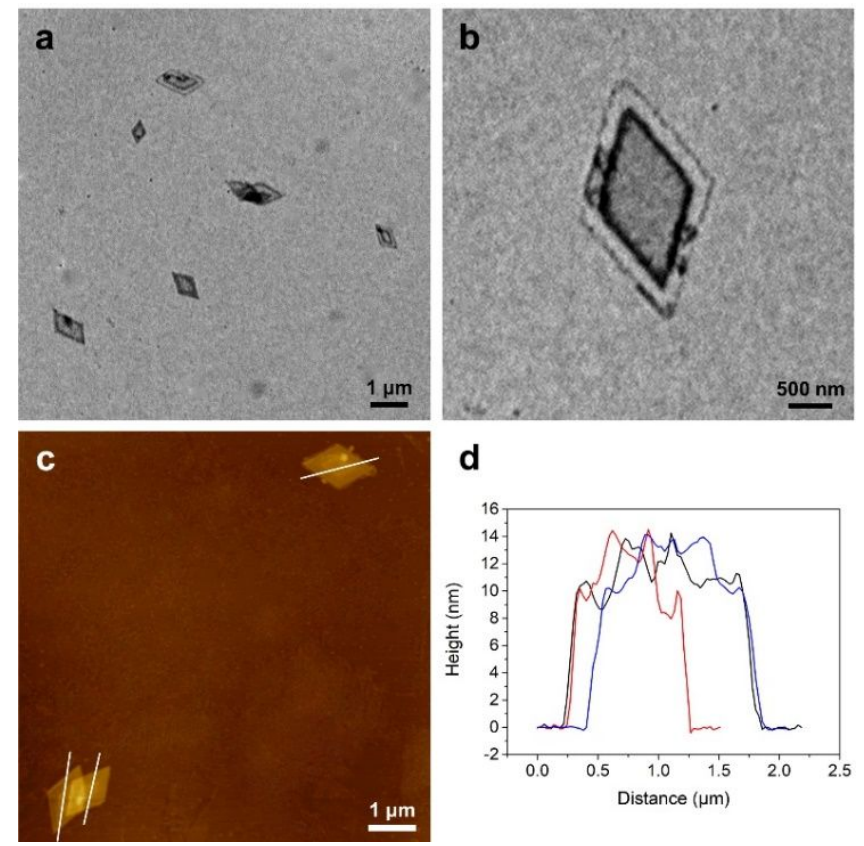

\section{d}

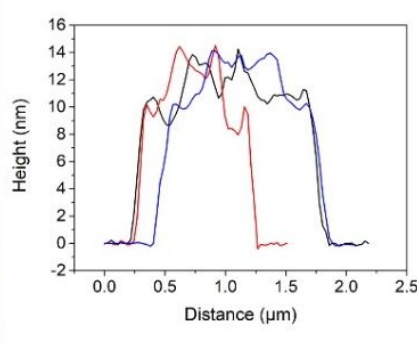

Figure S20. Diamond crystallites obtained from the CDSA of [DLA 32$]-b$-PEG. (a,b) TEM, (c) AFM images and (d) height profile. TEM samples were stained with a $1 \mathrm{wt} \%$ solution of phosphortungstic acid in water (CDSA conditions : $1 \mathrm{mg} / \mathrm{mL}$ in $\mathrm{EtOH}, 75^{\circ} \mathrm{C}$, slow cooling, $24 \mathrm{~h}$ aging, dilute with water $0.1 \mathrm{mg} / \mathrm{mL}$ ).
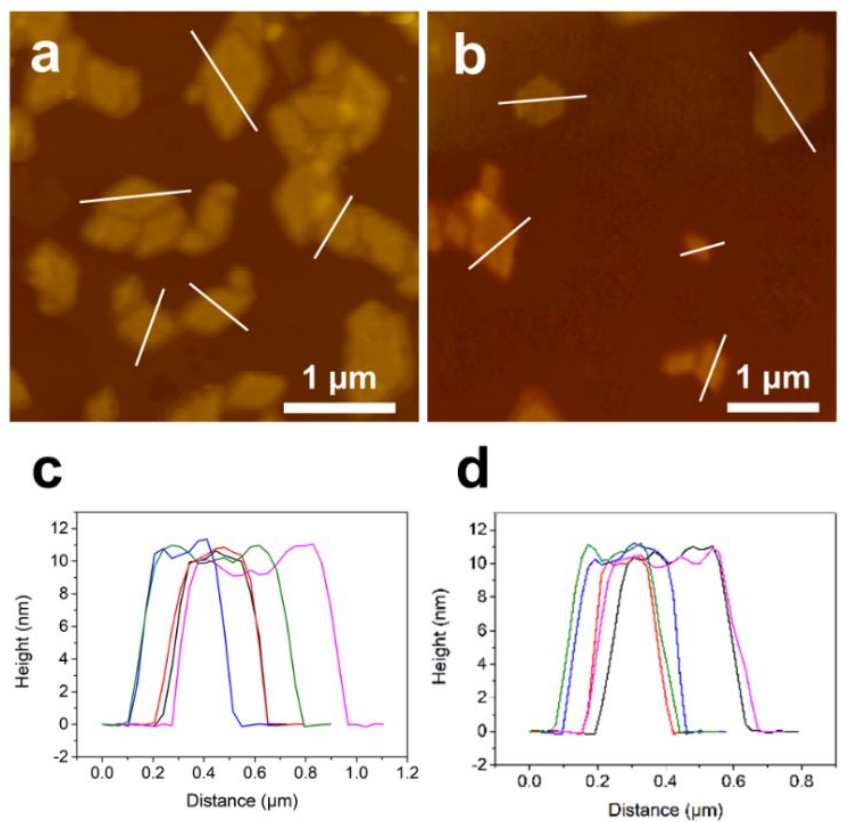

Figure S21. AFM images and height profiles obtained from the CDSA of $(\mathrm{a}, \mathrm{c})\left[\mathrm{DLA}_{32}\right]-b-\mathrm{PEG}$ or $(\mathrm{b}, \mathrm{d})\left[\mathrm{DLA}_{64}\right]-b$-PEG without water dilution (CDSA conditions : $1 \mathrm{mg} / \mathrm{mL}$ in EtOH, $75^{\circ} \mathrm{C}$, slow cooling, $24 \mathrm{~h}$ aging). 

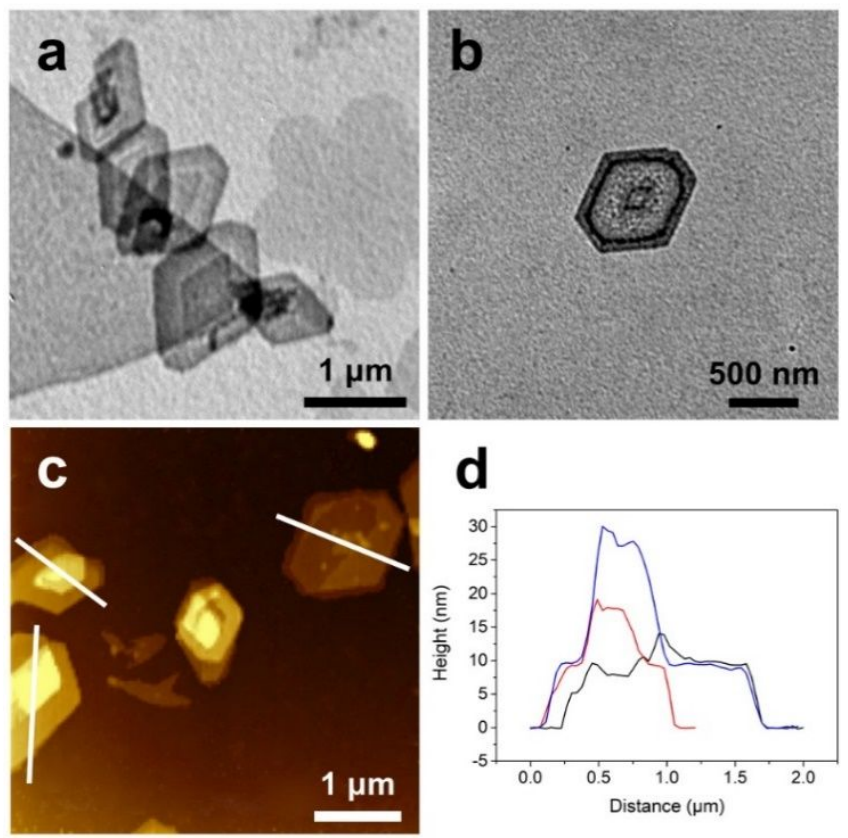

Figure S22. Truncated diamond crystallites obtained from the CDSA of [DLA 64$]-b-P E G .(a, b)$ TEM, (c) AFM images and (d) height profile. TEM samples were stained with a $1 \mathrm{wt} \%$ solution of phosphortungstic acid in water $\left(\mathrm{CDSA}\right.$ conditions : $1 \mathrm{mg} / \mathrm{mL}$ in $\mathrm{EtOH}, 75^{\circ} \mathrm{C}$, slow cooling, $24 \mathrm{~h}$ aging, dilute with water $0.1 \mathrm{mg} / \mathrm{mL}$ ).
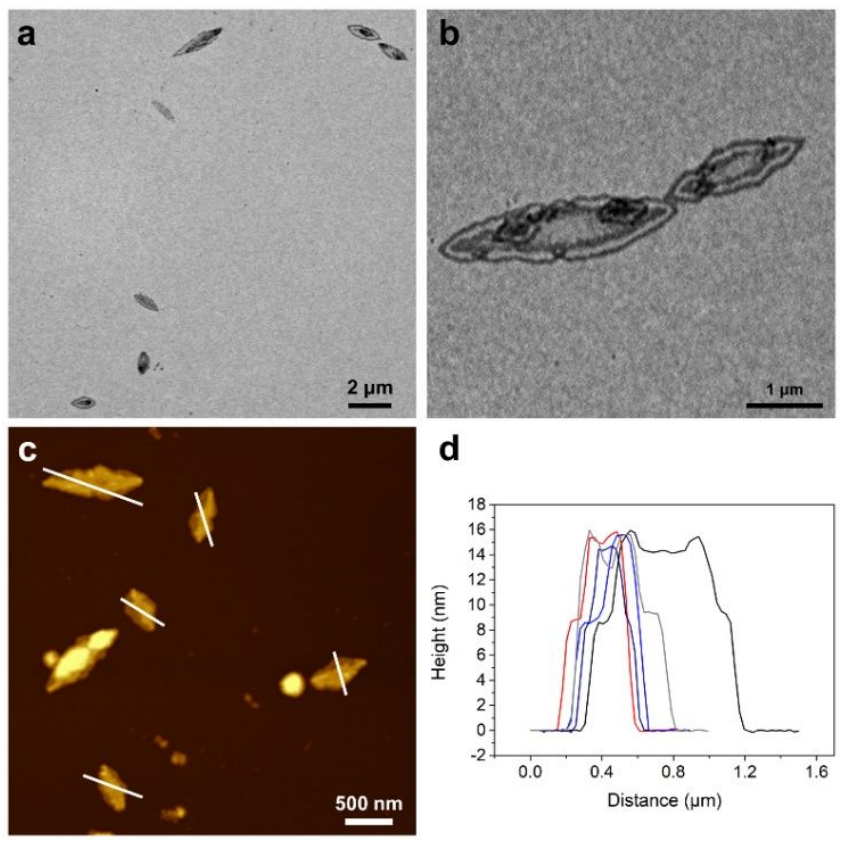

Figure S23. Leaf-like crystallites formed by the CDSA of [DLA $\left.\mathrm{D}_{40}\right]-b$-PEG. (a,b) TEM, (c) AFM images and (d) height profile. TEM samples were stained with a $1 \mathrm{wt} \%$ solution of phosphortungstic acid in water $\left(\mathrm{CDSA}\right.$ conditions : $1 \mathrm{mg} / \mathrm{mL}$ in $\mathrm{EtOH}, 75^{\circ} \mathrm{C}$, slow cooling, $24 \mathrm{~h}$ aging, dilute with water 
$0.1 \mathrm{mg} / \mathrm{mL})$.
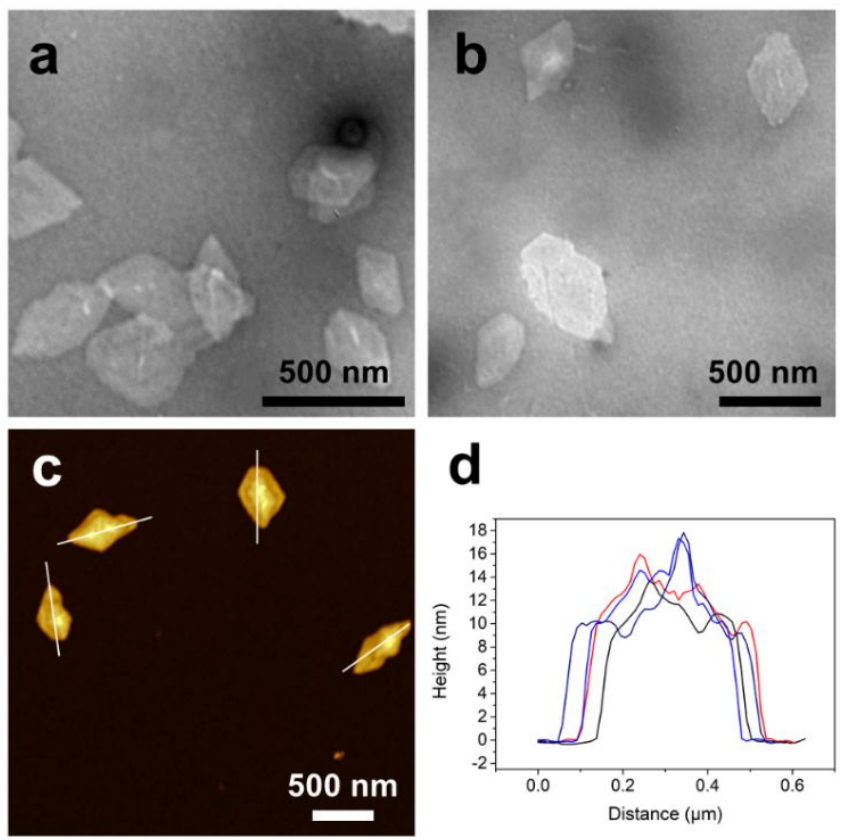

Figure S24. Leaf-like crystallites formed by the CDSA of [DLA 72$]-b$-PEG. (a,b) TEM, (c) AFM images and (d) height profile. TEM samples were stained with a $1 \mathrm{wt} \%$ solution of phosphortungstic acid in water. (CDSA conditions : $1 \mathrm{mg} / \mathrm{mL}$ in $\mathrm{EtOH}, 75^{\circ} \mathrm{C}$, slow cooling, $24 \mathrm{~h}$ aging, dilute with water $0.1 \mathrm{mg} / \mathrm{mL})$
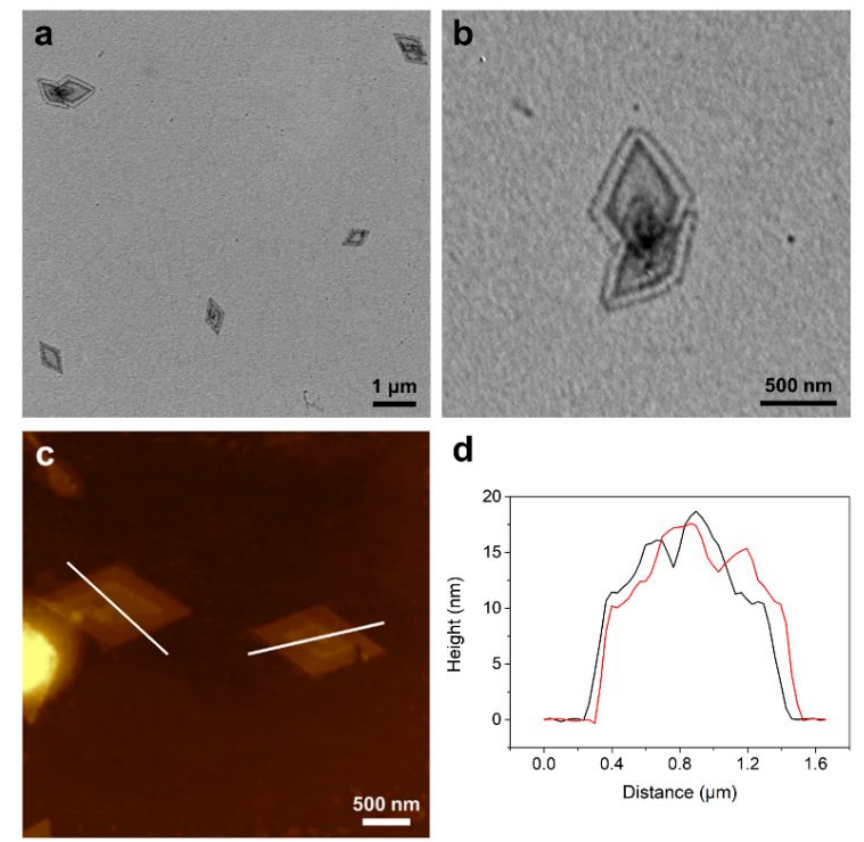

d

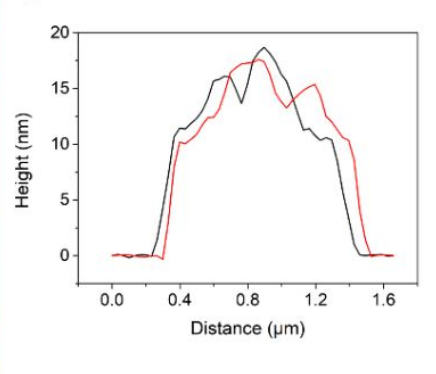

Figure S25. Diamond crystallites obtained from the CDSA of [DLA $\left.32-\mathrm{D} / \mathrm{LLA}_{8}\right]-b-\mathrm{PEG}$. (a,b) TEM, (c) AFM images and (d) height profile. TEM samples were stained with a $1 \mathrm{wt} \%$ solution of phosphortungstic acid in water (CDSA conditions : $1 \mathrm{mg} / \mathrm{mL}$ in $\mathrm{EtOH}, 75^{\circ} \mathrm{C}$, slow cooling, $24 \mathrm{~h}$ aging, 
dilute with water $0.1 \mathrm{mg} / \mathrm{mL}$ ).
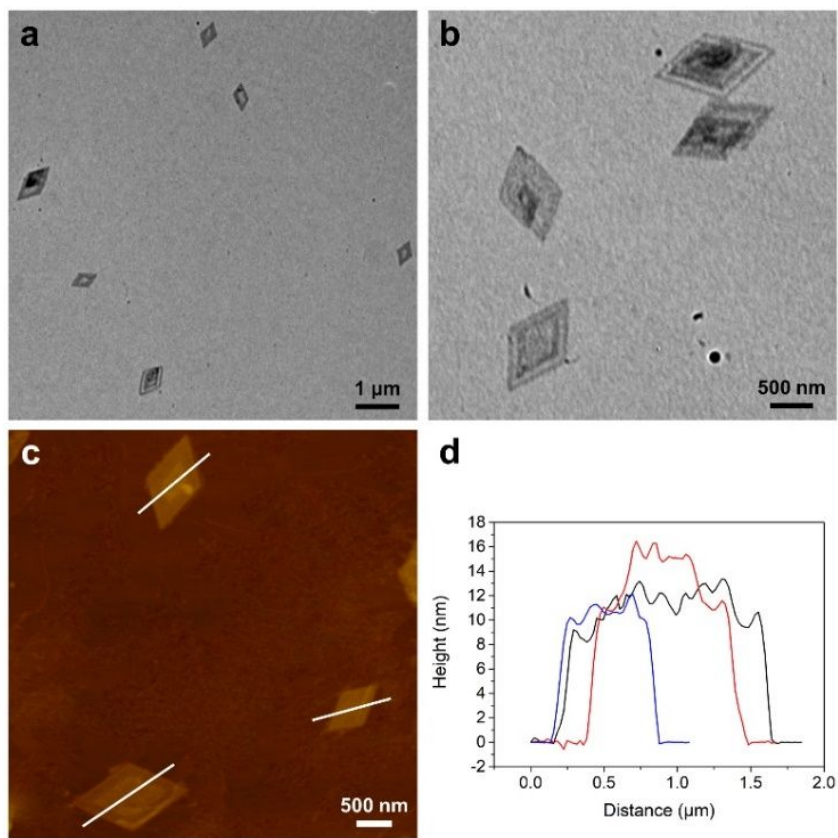

d

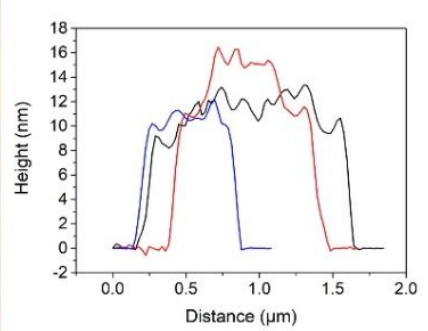

Figure S26. Diamond crystallites obtained from the CDSA of [DLA $\left.{ }_{32}-\mathrm{LLA}_{8}\right]-b$-PEG. (a,b) TEM, (c) AFM images and (d) height profile. TEM samples were stained with a $1 \mathrm{wt} \%$ solution of phosphortungstic acid in water (CDSA conditions : $1 \mathrm{mg} / \mathrm{mL}$ in EtOH, $75^{\circ} \mathrm{C}$, slow cooling, $24 \mathrm{~h}$ aging, dilute with water $0.1 \mathrm{mg} / \mathrm{mL}$ ). 

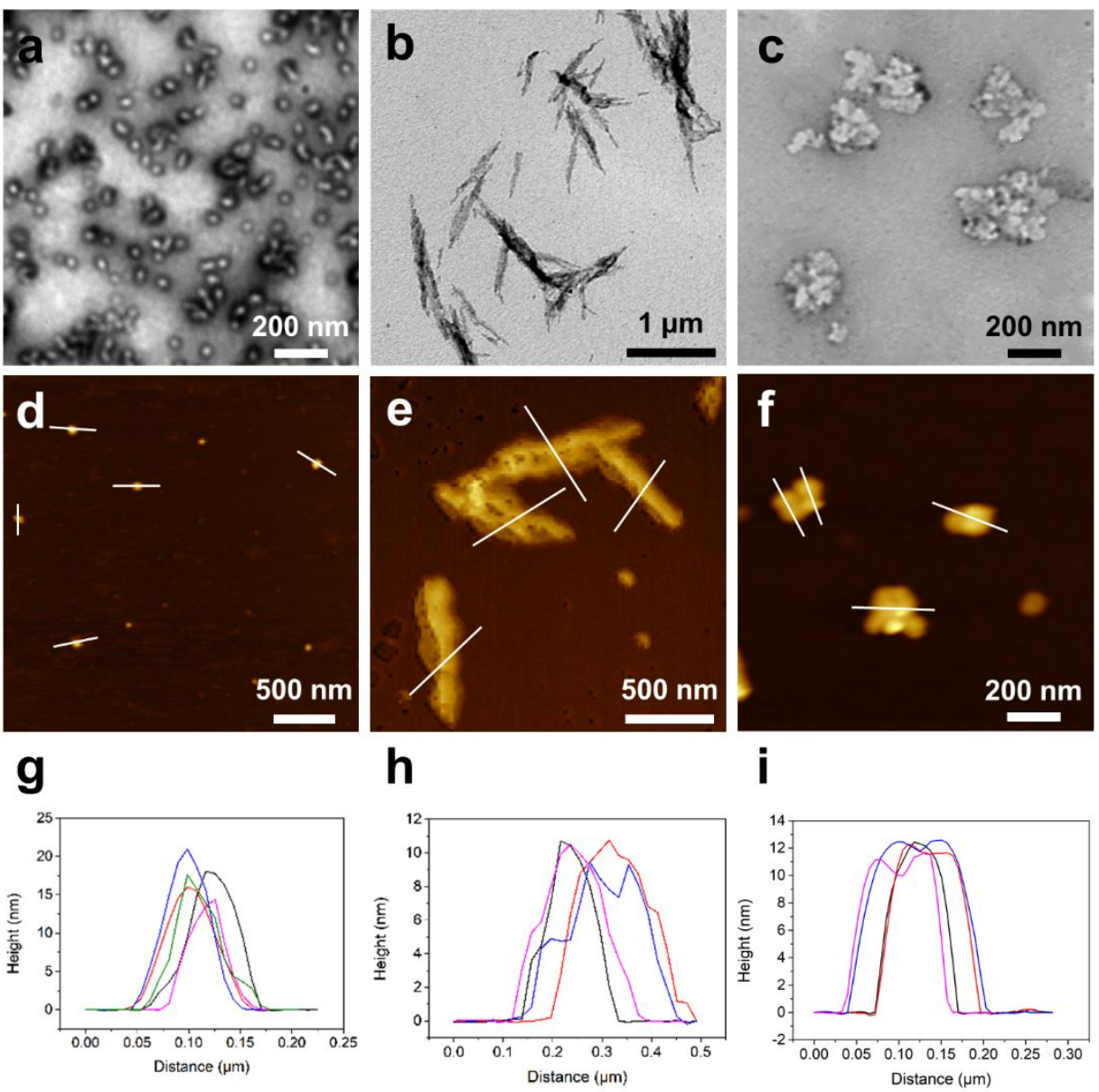

Figure S27. TEM and AFM images of the SCs of a pair of BCPs having complimentarily configured MPLA blocks. (a,d,g) SC [DLA 32$]-b$-PEG and [LLA 32$]-b$-PEG $(1: 1 \mathrm{~mol} / \mathrm{mol}) . \quad(\mathrm{b}, \mathrm{e}, \mathrm{h}) \mathrm{SC}\left[\mathrm{DLA}_{40}\right]-b-$ PEG and [LLA 40$]-b$-PEG (1:1 mol/mol). (c,f,i) SC [DLA 64$]-b$-PEG and [LLA 64 ]- $b$-PEG (1:1 mol/mol). TEM samples were stained with a $1 \mathrm{wt} \%$ solution of phosphortungstic acid in water (CDSA conditions : $1 \mathrm{mg} / \mathrm{mL}$ in EtOH, $75^{\circ} \mathrm{C}$, slow cooling, $24 \mathrm{~h}$ aging, dilute with water $0.1 \mathrm{mg} / \mathrm{mL}$ ). 


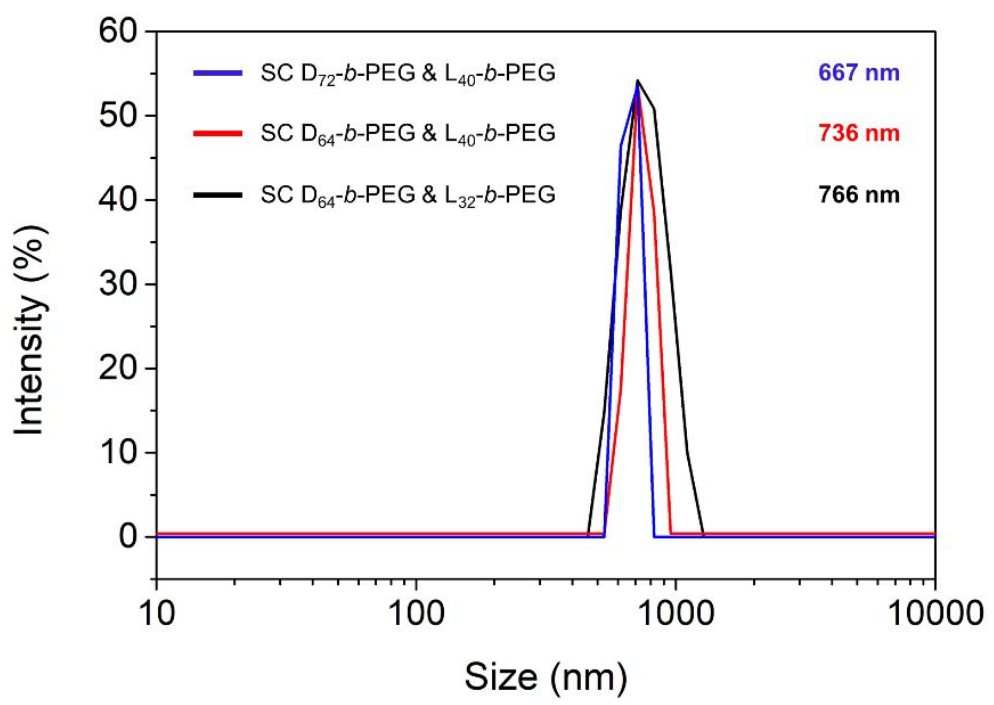

Figure S28. Dynamic light scattering (DLS) size plots of vesicles from co-self-assembly of [DLA $\mathrm{D}_{\mathrm{n}}$ $b$-PEG/[LLA $\left.{ }_{\mathrm{m}}\right]-b$-PEG $(\mathrm{n}>\mathrm{m}, 1: 1 \mathrm{~mol} / \mathrm{mol}, \mathrm{D} / \mathrm{L} \geq 1.600)$. 

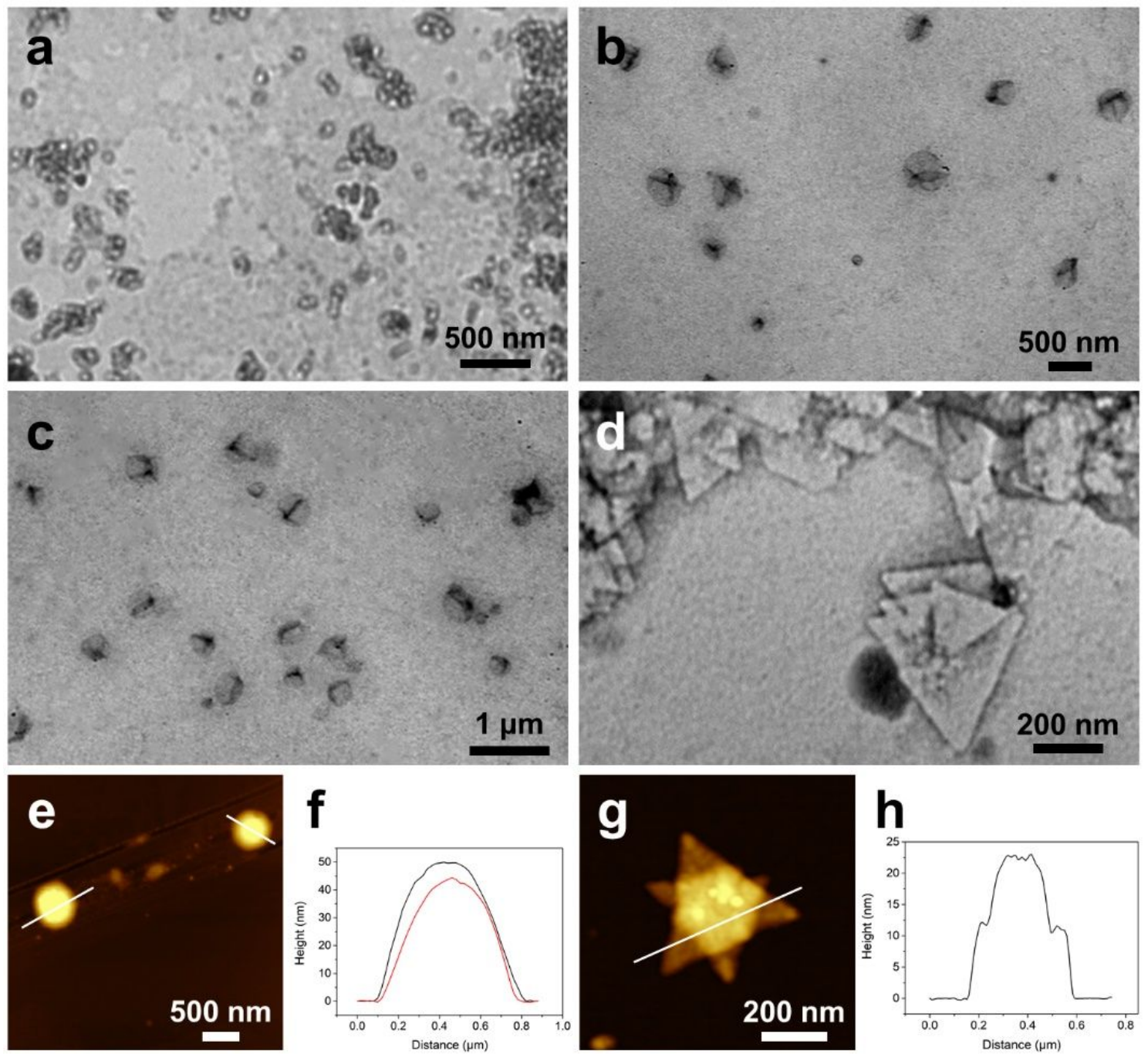

Figure S29. Assembled structures with different shapes from size mismatched SCs. (a-d) TEM images of incomplete SC. (a) Nanoparticles prepared by co-self-assembly of [DLA $\left.\mathrm{DL}_{40}\right]-b$-PEG/[LLA 32$]-b$-PEG $(1: 1 \mathrm{~mol} / \mathrm{mol}, \mathrm{D} / \mathrm{L}=1.250)$. (b) Vesicles formed through co-self-assembly of [DLA 64$]-b-\mathrm{PEG} /\left[\mathrm{LLA}_{40}\right]-$ $b$-PEG $(1: 1 \mathrm{~mol} / \mathrm{mol}, \mathrm{D} / \mathrm{L}=1.600)$. (c) Vesicles formed through co-self-assembly of [DLA 72$]-b$ PEG/[LLA 40$]-b$-PEG $(1: 1 \mathrm{~mol} / \mathrm{mol}, \mathrm{D} / \mathrm{L}=1.800)$. (d) Triangular $2 \mathrm{D}$ structures prepared by co-selfassembly of [DLA 72$]-b-\mathrm{PEG} /\left[\mathrm{LLA}_{64}\right]-b-\mathrm{PEG}(1: 1 \mathrm{~mol} / \mathrm{mol}, \mathrm{D} / \mathrm{L}=1.125)$. (e,f) AFM image and height profile of vesicles formed by co-self-assembly of [DLA 64$]-b$-PEG/[LLA 40$]-b-P E G(1: 1 \mathrm{~mol} / \mathrm{mol}, \mathrm{D} / \mathrm{L}=$ 1.600). (g,h) AFM image and height profile of triangular 2D structures by co-self-assembly of $\left[\mathrm{DLA}_{72}\right]-b-\mathrm{PEG} /\left[\mathrm{LLA}_{64}\right]-b-\mathrm{PEG}(1: 1 \mathrm{~mol} / \mathrm{mol}, \mathrm{D} / \mathrm{L}=1.125)$. TEM samples were stained with a $1 \mathrm{wt} \%$ solution of phosphortungstic acid in water (CDSA conditions : $1 \mathrm{mg} / \mathrm{mL}$ in EtOH, $75^{\circ} \mathrm{C}$, slow cooling, $24 \mathrm{~h}$ aging, dilute with water $0.1 \mathrm{mg} / \mathrm{mL}$ ). 


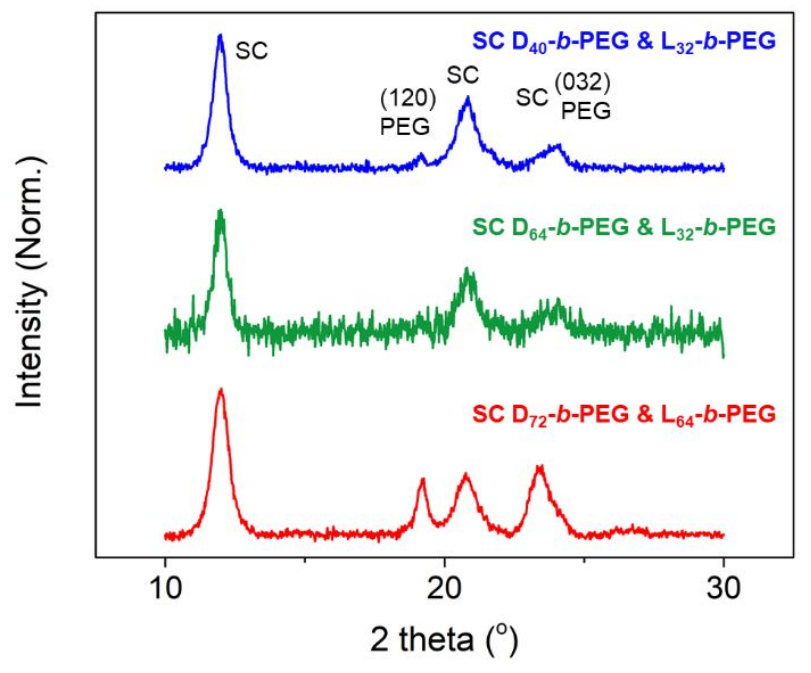

Figure S30. XRD plots of the crystallite from the BCPs in EtOH solution. SC [DLA 40 ]- $b$-PEG \& $\left[\mathrm{LLA}_{32}\right]-b$-PEG (blue); SC [DLA 64 ]- $b$-PEG \& [LLA 32 ]- $b$-PEG (green); SC [DLA 72$]-b$-PEG \& [LLA 64 ]$b$-PEG (red). ${ }^{3,4}$ 

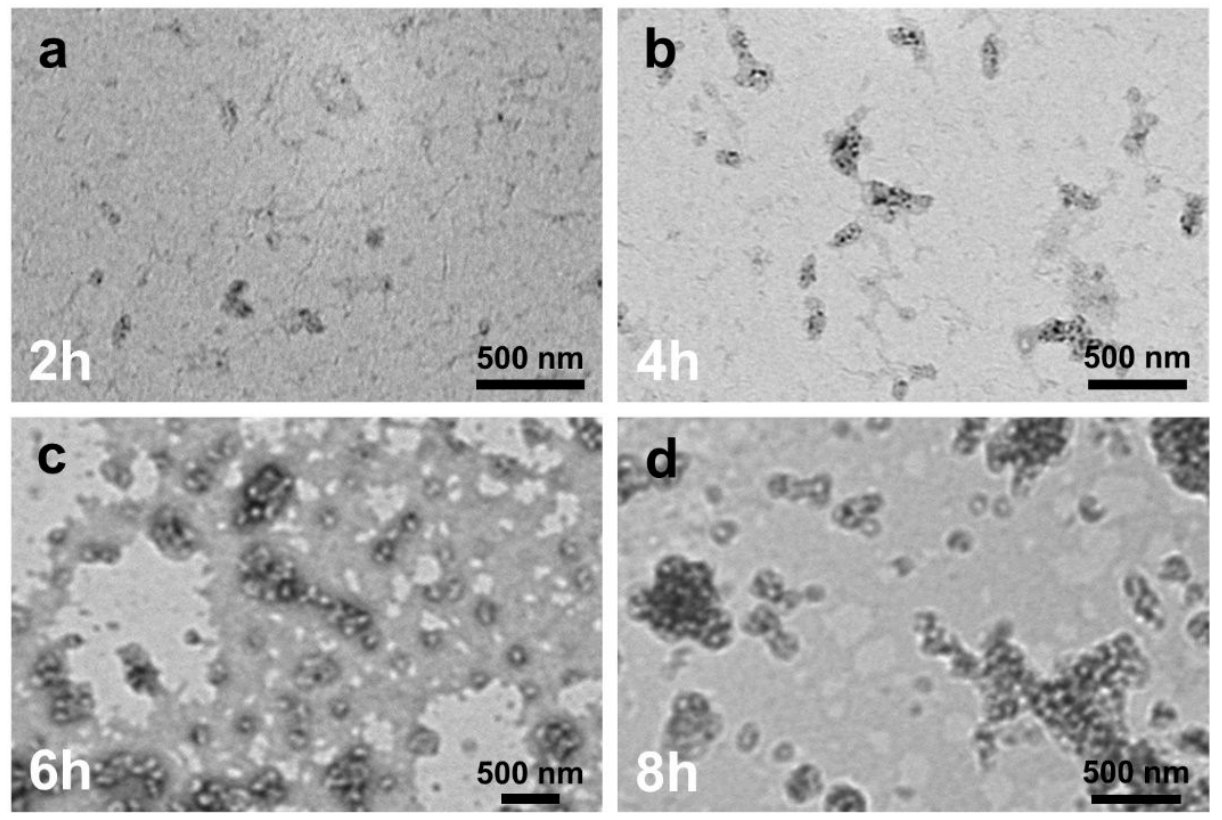

Figure S31. TEM images of different time points of the SCs having complimentarily configured MPLA blocks, [DLA 32$]-b$-PEG and [LLA 32$]-b$-PEG (1:1 mol/mol). (a) 2 hours after starting the aging. (b) 4 hours. (c) 6 hours. (d) 8 hours (CDSA conditions : $1 \mathrm{mg} / \mathrm{mL}$ in EtOH, $75^{\circ} \mathrm{C}$, slow cooling, dilute with water $0.1 \mathrm{mg} / \mathrm{mL})$.
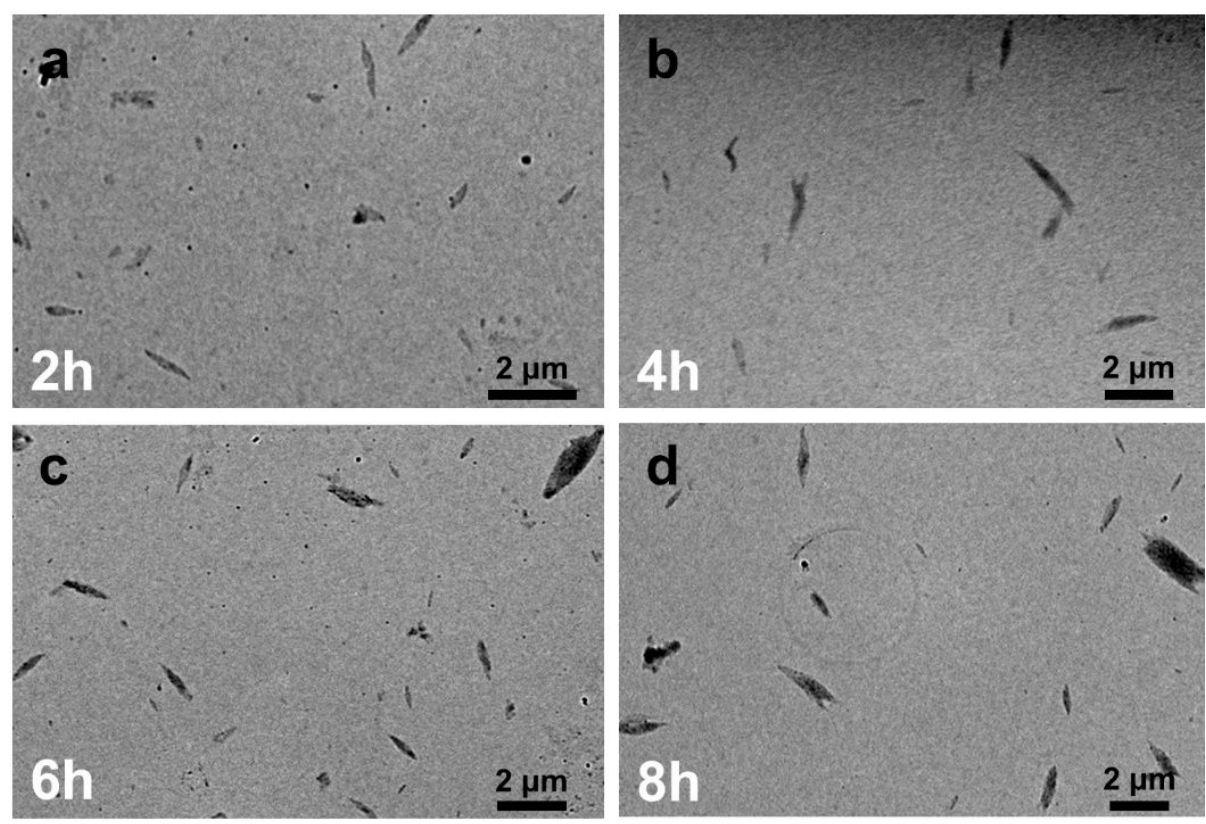

Figure S32. TEM images of different time points of the SCs having complimentarily configured MPLA blocks, [DLA 40 ]- $b$-PEG and [LLA 40 ]- $b$-PEG $(1: 1 \mathrm{~mol} / \mathrm{mol})$. (a) 2 hours after starting the aging. (b) 4 hours. (c) 6 hours. (d) 8 hours (CDSA conditions : $1 \mathrm{mg} / \mathrm{mL}$ in EtOH, $75^{\circ} \mathrm{C}$, slow cooling, dilute with water $0.1 \mathrm{mg} / \mathrm{mL}$ ) 


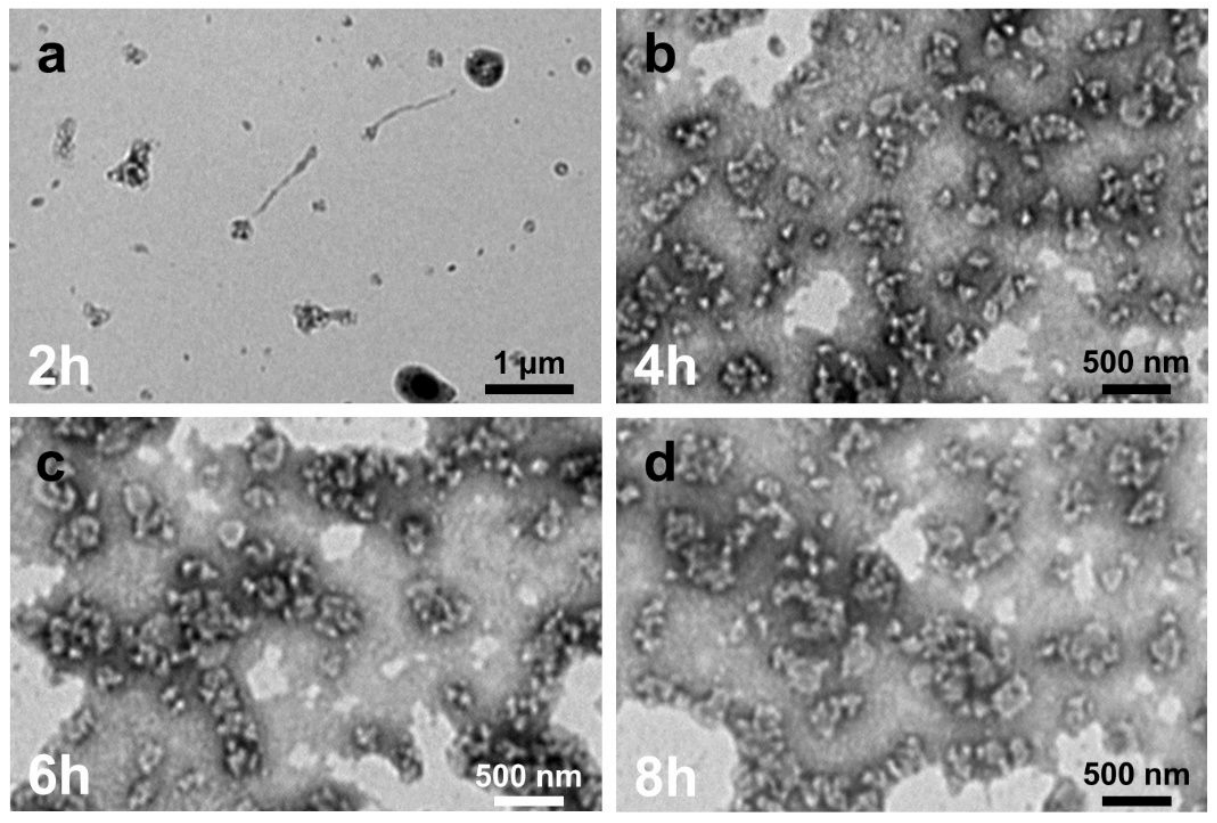

Figure S33. TEM images of different time points of the SCs having complimentarily configured MPLA blocks, [DLA 64 ]- $b$-PEG and [LLA 64 ]- $b$-PEG (1:1 mol/mol). (a) 2 hours after starting the aging. (b) 4 hours. (c) 6 hours. (d) 8 hours (CDSA conditions : $1 \mathrm{mg} / \mathrm{mL}$ in EtOH, $75^{\circ} \mathrm{C}$, slow cooling, dilute with water $0.1 \mathrm{mg} / \mathrm{mL}$ ). 


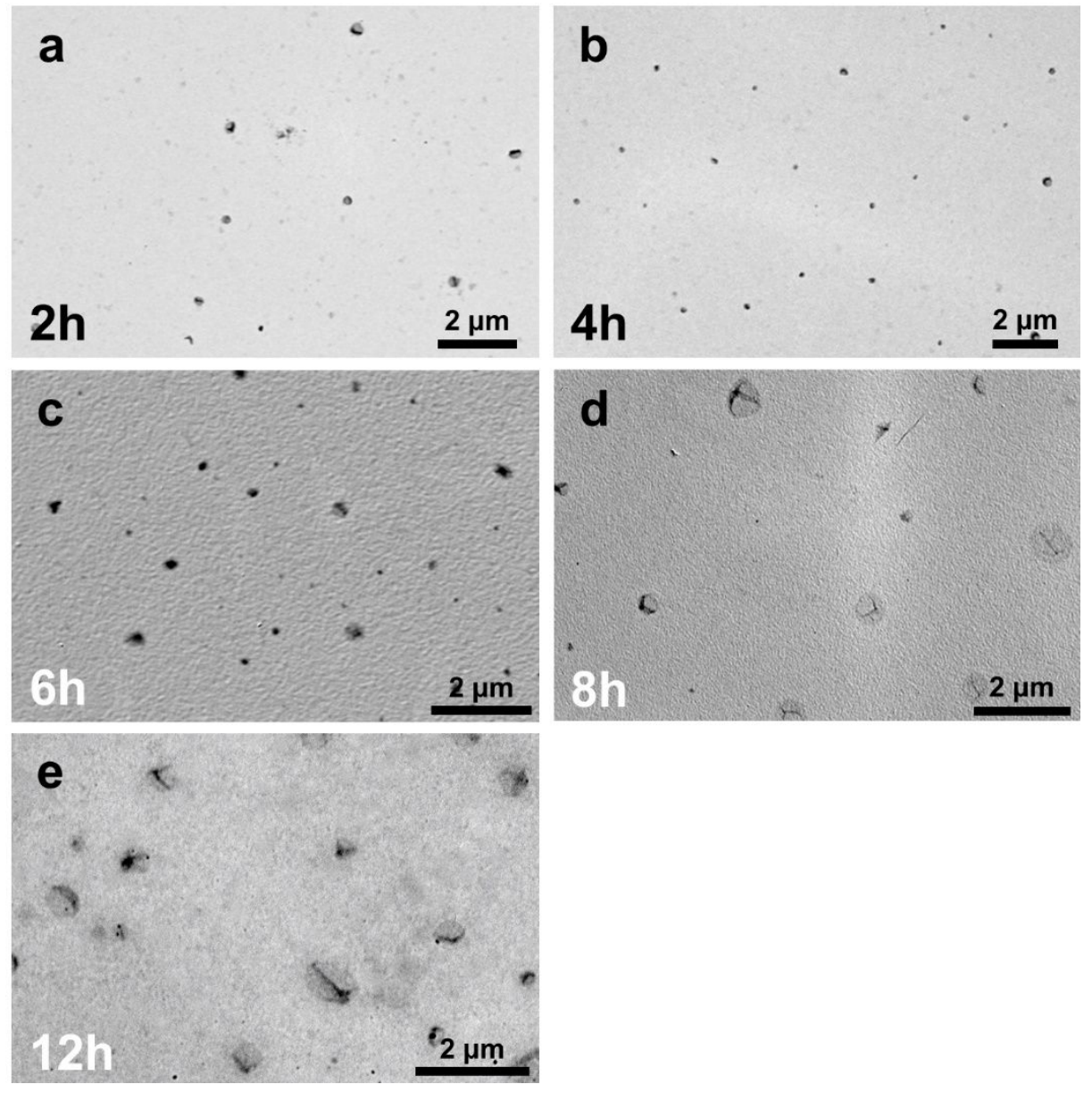

Figure S34. TEM images of different time points of the SCs having a mismatch in the size of MPLA blocks, [DLA 64$]-b$-PEG and [LLA 32$]-b$-PEG $(1: 1 \mathrm{~mol} / \mathrm{mol}, \mathrm{D} / \mathrm{L}=2.000)$. (a) 2 hours after starting the aging. (b) 4 hours. (c) 6 hours. (d) 8 hours. (e) 12 hours (CDSA conditions : $1 \mathrm{mg} / \mathrm{mL}$ in EtOH, $75^{\circ} \mathrm{C}$, slow cooling, dilute with water $0.1 \mathrm{mg} / \mathrm{mL})$. 

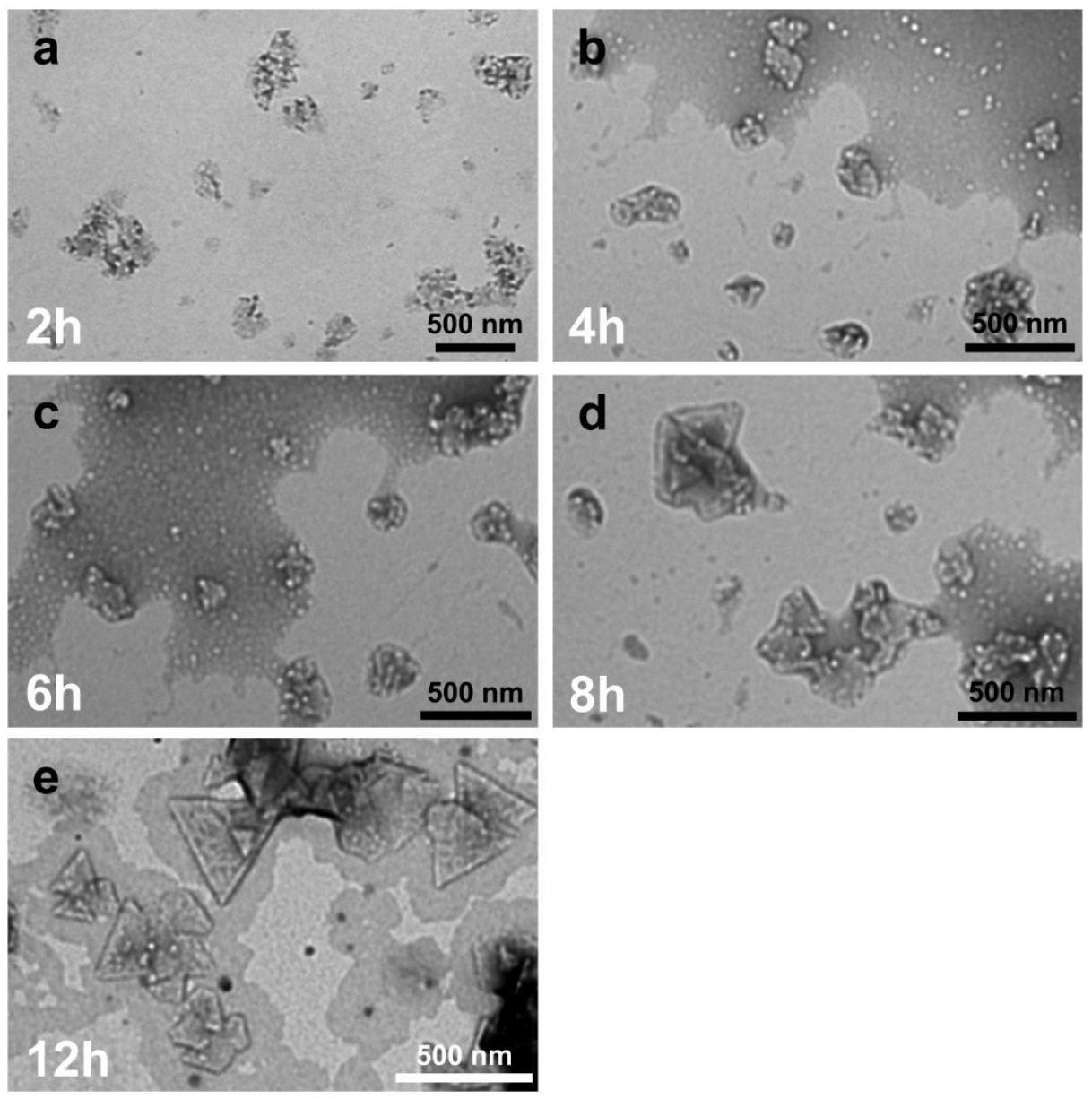

Figure S35. TEM images of different time points of the SCs having a mismatch in the size of MPLA blocks, [DLA 72$]-b$-PEG and [LLA 64 ]- $b$-PEG $(1: 1 \mathrm{~mol} / \mathrm{mol}, \mathrm{D} / \mathrm{L}=1.125)$. (a) 2 hours after starting the aging. (b) 4 hours. (c) 6 hours. (d) 8 hours. (e) 12 hours (CDSA conditions : $1 \mathrm{mg} / \mathrm{mL}$ in EtOH, $75^{\circ} \mathrm{C}$, slow cooling, dilute with water $0.1 \mathrm{mg} / \mathrm{mL})$. 

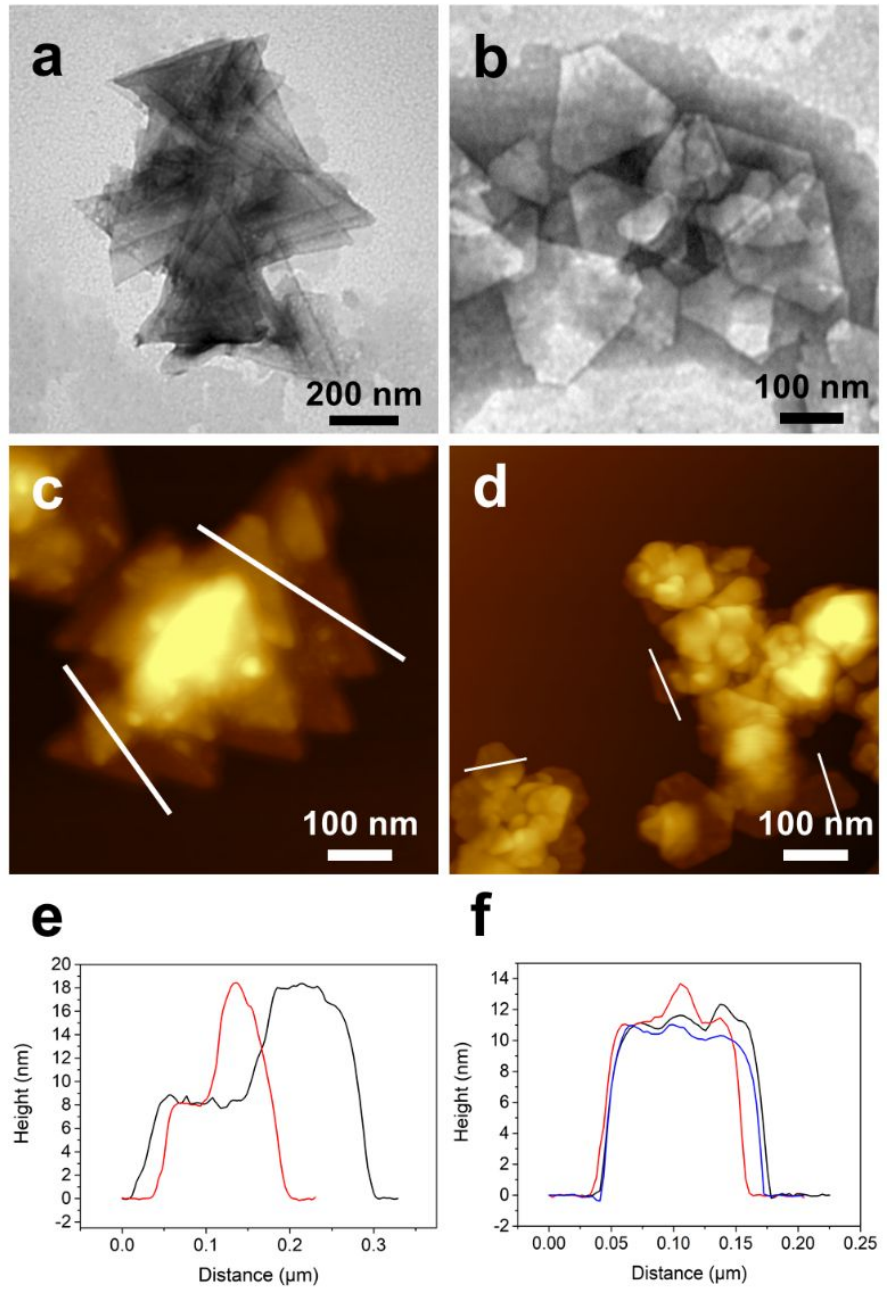

Figure S36. 2D crystallites formed through SCs having stereochemical sequence. (a,b) TEM images, (c-f) AFM images and height profiles of SC crystallites. (a,c,e) Triangular 2D structures by co-selfassembly of $\left[\mathrm{DLA}_{32}\right.$-D/LLA 8 - $b$-PEG/ [LLA 40$]-b$-PEG $(1: 1 \mathrm{~mol} / \mathrm{mol})$. (b,d,f) Truncated triangular 2D structures by co-self-assembly of [DLA $\left.{ }_{32}-\mathrm{LLA}_{8}\right]-b$-PEG/[LLA 40$]-b$-PEG $(1: 1 \mathrm{~mol} / \mathrm{mol})$. TEM samples were stained with a $1 \mathrm{wt} \%$ solution of phosphortungstic acid in water (CDSA conditions : $1 \mathrm{mg} / \mathrm{mL}$ in $\mathrm{EtOH}, 75^{\circ} \mathrm{C}$, slow cooling, $24 \mathrm{~h}$ aging, dilute with water $0.1 \mathrm{mg} / \mathrm{mL}$ ). 


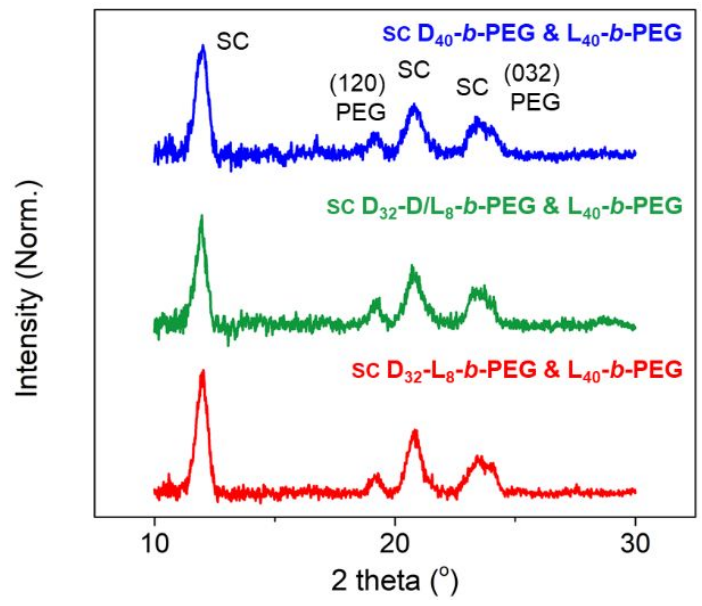

Figure S37. XRD plots of the crystallite from the BCPs in EtOH solution. SC [DLA 40 ]- $b-\mathrm{PEG} \&$

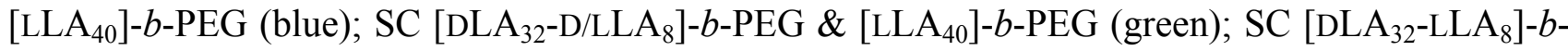
PEG \& [LLA 40$]-b$-PEG (red)..$^{3,4}$ 


\section{References}

(1) Takizawa, K.; Nulwala, H.; Hu, J.; Yoshinaga, K.; Hawker, C. J. Molecularly defined (L)-lactic acid oligomers and polymers: Synthesis and characterization. J. Polym. Sci. Part A: Polym. Chem. 2008, 46, 5977-5990.

(2) Inam, M.; Cambridge, G.; Pitto-Barry, A.; Laker, Z. P. L.; Wilson, N. R.; Mathers, R. T.; Dove, A. P.; O'Reilly, R. K. 1D vs. 2D shape selectivity in the crystallization-driven self-assembly of polylactide block copolymers. Chem. Sci. 2017, 8, 4223-4230.

(3) Yang, J.; Zhao, T.; Cui, J.; Liu, L.; Zhou, Y.; Li, G.; Zhou, E.; Chen, X. J. Polym. Sci. Part B 2006, $44,3215-3226$.

(4) Lamers, B. A. G.; van Genabeek, B.; Hennissen, J.; de Waal, B. F. M.; Palmans, A. R. A.; Meijer, E. W. Stereocomplexes of Discrete, Isotactic Lactic Acid Oligomers Conjugated with Oligodimethylsiloxanes. Macromolecules 2019, 52, 1200-1209. 